\title{
الاعتبارات الإرجونوميكية الواجب مراعاتها عند تصميم المقابض الوظيفية بالمنتجات الصناعية
}

\section{Ergonomic Considerations to be Taken into Account in Designing} Functional Knobs for Industrial Products

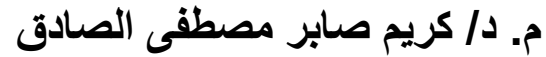

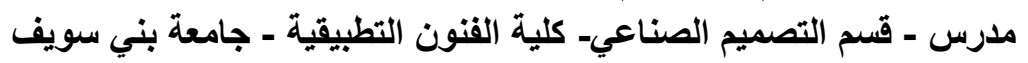 \\ Dr. Kareem Saber Mustafa \\ Industrial design Dept., Faculty of Applied Arts \\ Beni-Suef University, Egypt \\ karim.designhome@apparts.bsu.edu.eg
}

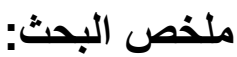

يهدف علم الإرجونوميكس إلى تصميم المنتجات المختلفة التى يتعامل معها المستخدمون بما يحقق لهم الر احة و الأمان، لذلك أُطلق على علم الإرجونوميكس "فن التصميم لر احة ورفاهية البشر". وبالنظر إلى المنتجات الصناعية المختلفة، يلاحَظ أنه

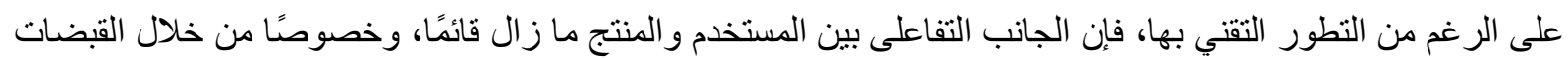

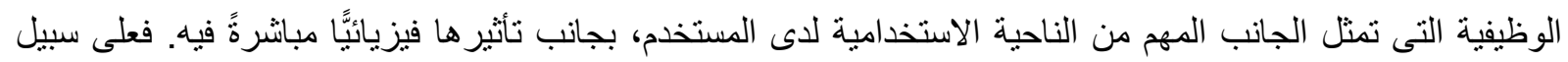

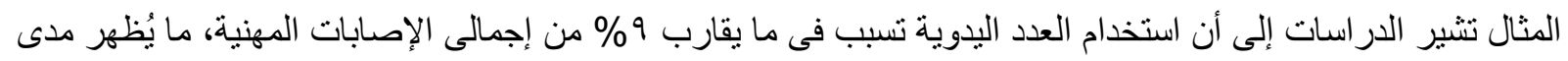

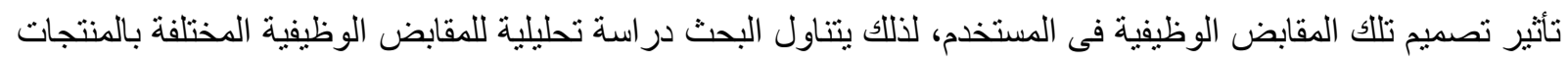
الصناعية، التى تعتمد بقدر كبير على التفاعل المباشر بينها وبين المستخدم، وتتطلب منه ضرورة استخدام اليدين و الذر اعين بقوة معينة ليتمكن من استخدامها والتحكم فيها، للوصول إلى وضع مجموعة من الاعتبار ات الإرجونوميكية كمرجعية للمصممين ودارسى التصميم الصناعى، لمساعدتهم على تصميم تلك المقابض الوظيفية بالمنتجات المختلفة، وتحسين الوظيفة الاستخدامية و الإرجونوميكية لها، بما يضمن توفير الراحة والأمان للمستخدمين كافة بجميع فئاتهم و أعمار هم.

الكلمات المفتاحية: المستخدم- المصمم الصناعى- علم الإرجونوميكس- إصابات العمل- التصميم الصناعى- العدد اليدوية.
\end{abstract}

\begin{abstract}
:
Ergonomics is the process of designing different products that users deal with in a way to ensure comfort and safety for them, therefore ergonomics is known as the art of design to offer better luxury and comfort for people. For various industrial products, despite their technical development however the interactive side between them and the user still exists, specifically for functional knobs which represent their importance for user in addition to their direct physical effect on him/her. For example, studies indicate the use of hand tools is in response to which approximately $9 \%$ of the overall occupational injuries which shows the effect of designing functional knobs on user (Aghazadeh,1986). This research addresses an analytical study of the various functional knobs in industrial products in which it depends on a direct interaction between them and the user and requires him/her to use hands and arms with a certain force to be able to use and control them in which it will lead to have a set of ergonomic considerations as a reference for designers and industrial design students in order to help them in designing
\end{abstract}


their functional knobs with different products and improving their usability and ergonomical function of them in a way to ensure comfort and safety for all users of all categories and ages.

\section{Keywords:}

User, Industrial designer, Ergonomics, Occupational Injuries, Industrial Design, Hand Tools.

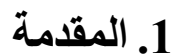

ظهر علم الإرجونوميكس (Ergonomics) كعلم قادر على تقديم حلول تصميمية للمشكلات المترنبة على تفاعل المستخدم

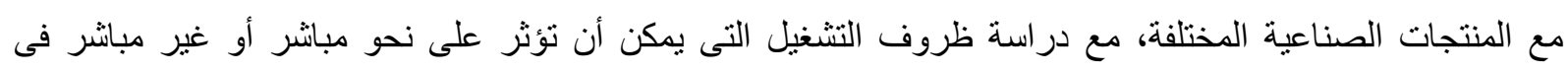

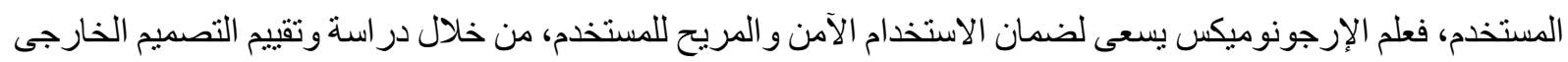
للمنتج، و التأكد من مدى قدرته على مساعدة المستخدمين على أداء وظائفهم بصورة أسهل و أسرع، مع تقليل نسبة الخطأ التى تنشأ عن عمليات التشغيل و التفاعل بين المستخدم و المنتج إلى أدنى مستوى مدكن.

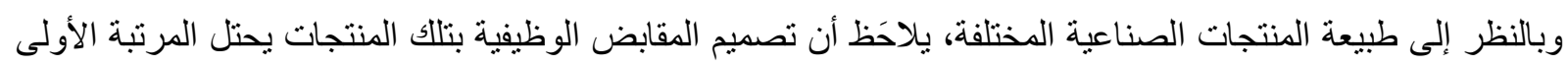
من حيث العلاقة والتفاعل بين المستخدم والمنتج، حيث تعد تلاك القبضات الوسيلة الأولى لمساعدة المستخدم على استخدام المنتج و التحكم فيه، لذلك فإن أى قصور فى تصميم تلك المقابض باختلاف صور ها يمكن أن يؤثر مباشرةً فى المستخدم،

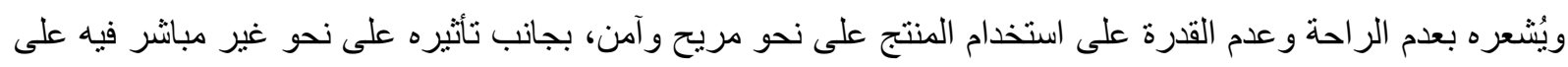
المدى الطويل، من خلال ظهور مشكلات جسدية و عضلية لديه، لذلك فان التصميم الصحيح للقبضة الوظيفية يؤدئ ولى إلى أداء استخدامى أفضل للمستخدم.

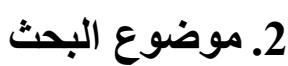
يعتمد الكثير من المنتجات الصناعية و الخدمات على الجانب العضلى للمستخدم، من خلال استخدام ذر اعيه ويديه ليتمكن من استخدامه على النحو الأمتل، بجانب إحكام السيطرة على المنتج و القدرة على تحريكه، لذلك فإن تصميم المقبض الوظيفى

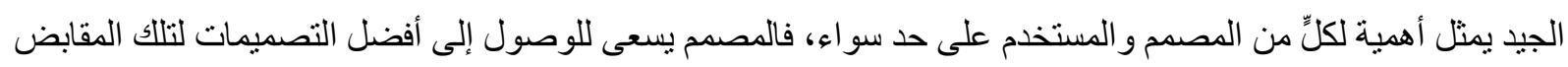

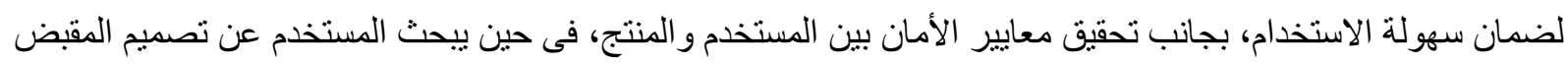
المريح حتى بتمكن من أداء الوظيفة من دون وجود عائق بينه وبين المنتج. لذلك فإن تصميم المقابض الوظيفية يمثل أهية قصوى فى مجال تصميم المنتجات، وعادةً بسعى الباحثون من خلال علم الإرجونوميكس إلى الوصول إلى مجموعة المتطلبات والمعايير الواجب مر اعاتها عند تصميم تلك المقابض، حتى يتمكن

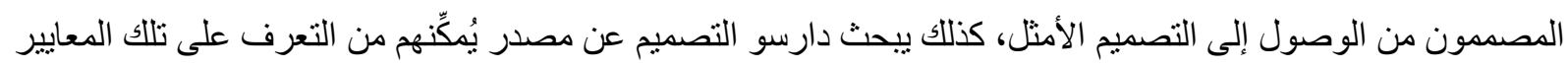
ودر استها، لمساعدتهم فى المستقبل على تقديم حلول تصميمية للمقابض الوظيفية تلاءم طبيعة المستخدم.

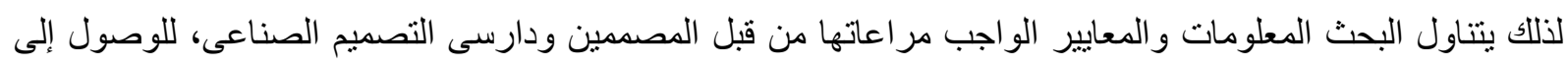
تصميم مقبض جيد يلاءم المستخدم ويحقق معايير الأمان عند الاستخدام.

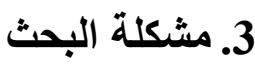
تتمثل مشكلة البحث فى عدم نو افر قائمة واضحة ومرتبة بالاعتبار ات الإرجونوميكية الواجب مر اعاتها من قبل المصممين ودارسى التصميمات الصناعية عند تصميم المقابض الوظيفية بالمنتجات الصناعية، ما ينعكس بالسلب على أداء المنتج وطبيعة العلاقة التفاعلية بين المستخدم والمنتج. 
يهدف البحث إلى وضع قائمة بالاعنبار ات الإرجونوميكية الو اجب مر اعاتها من قبل المصممين ودارسى التصميم الصناعى عند تصميم المقابض الوظيفية المختلفة بالمنتجات.

\section{5 أهمية البحث \\ تتمثل أهمية البحث في الآتي:}

• توضيح أهمية علم الإرجونوميكس والدور الذي يلعبه فى تطوير وتحسين المنتجات.

• ت توضيح دور المقابض الوظيفية الذي تلعبه فى العلاقة التفاعلية بين المستخدم والمنتج.

• وضع قائمة بالاعتبار ات الو اجب مر اعاتها عند تصميم المقابض الوظيفية من قبل مصممى ودارسي التصميم الصناعى.

• القدرة على الوصول إلى تصميمات لمقابض وظيفية بالمنتجات الصناعية تحقق الأمان و الراحة للمستخدمين.

6. منهج البحث يتبع البحث المنهج الوصفى التحليلى للوصول إلى منهجية تساعد الدارس على وضع المنطلبات الواجب مراعاتها عند تصميم المقابض الوظيفية.

\section{7. فرض البحث}

إن وضع قائمة بالاعتبار ات الإرجونوميكية الخاصة بتصميم المقابض الوظيفية بالمنتجات الصناعية كمرجعية لكلٍ من مصممى ودارسى التصميم الصناعى، سيؤدى إلى الوصول إلى تصميم مناسب وملائم للمستخدم.

8.

1-1 الاعتبارات الإرجونوميكية الواجب مراعاتها عند تصميم المقابض الوظيفية بالمنتجات الصناعية

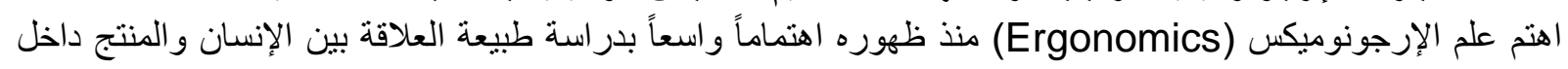

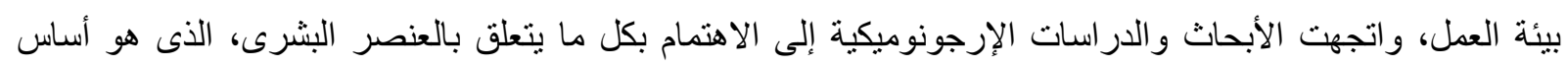

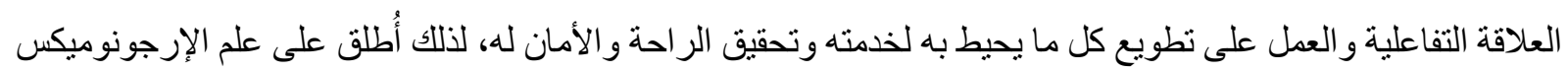
"علم وفن تصميم الأشياء بما يتناسب مع طبيعة البشر (المستخدمين). ويعد علم الإرجونوميكس مجاًلا تطبيفيًا مشتركًا بين علوم مختلفة، حيث يتطلب من دارسيه المعرفة بعلوم كثيرة، مثل علم التشريح (Anatomy)، و علم الأنثروبومترى (Anthropometry)، وكذلك علم السيكولوجى (Psychology)، و غير ها من العلوم التى تكتمل فى ما بينها للوصول إلى علم الإرجونوميكس، ما يجعل وضع تعريف محدد لذللك العلم من

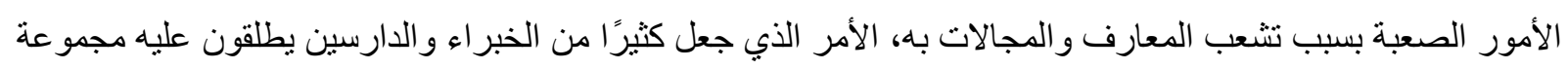

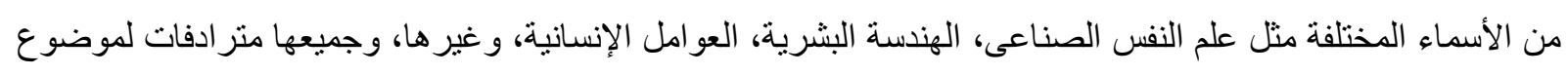

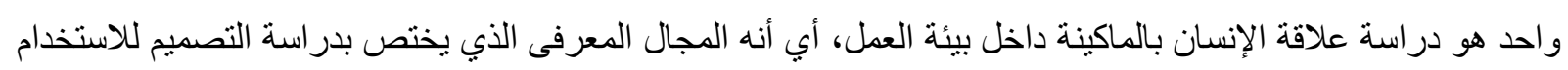
الإنسانى الأفضل والأمثل (Ebud Alnabaa, 2000) ،وبالنظر إلى مصطلح كلمة الإرجونوميكس (Ergonomics)

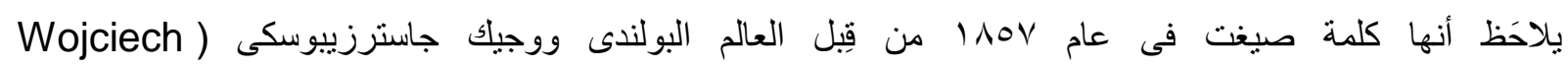

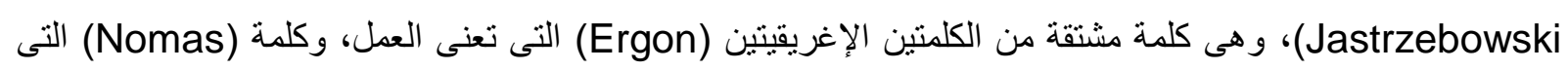

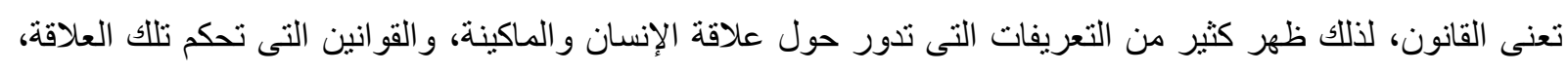
و وانعكاس ذلك على المستخدم. فعلى سبيل المثال عرَّفت جمعية الإرجونوميكس الأوروبية ( The Ergonomics (Society Europe 
و البيئة التى يعملون خلالها، فإذا ما تحقق هذا التو افق والملائمة على نحو جيد، فإن الضغوط التى تقع على البشر ستقل

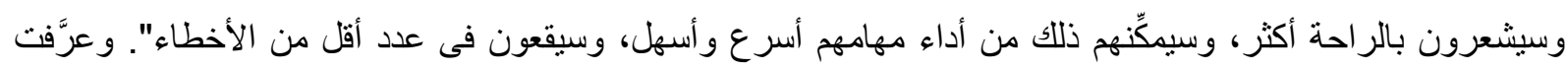

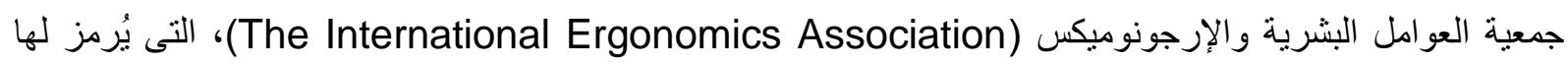
بالرمز (HFES)، علم الإرجونوميكس بأنه "العلم الذى يهتم بالتأكد من أن الآلات والأدوات و الأثاث المتعلق بأداء مهمة

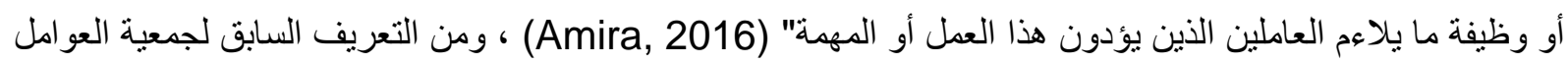
البشرية والإرجونوميكس تظهر أهمية تصميم العدد البدوية والأدوات بما يلاءم المستخدم، فكلما كان التصميم أفضل ملائمة للمستخدم، أدى ذلك إلى تقليل الأخطاء والآثار المتعلقة بعملية الاستخدام على المستخدم، فالتصميم الصحيح للأداة بعد مهمًًا للوقاية من الاضطر ابات العضلية المختلفة التى تحدث فى الأطر اف العلوية عند المستخدم بسبب طبيعة الاستخدام.

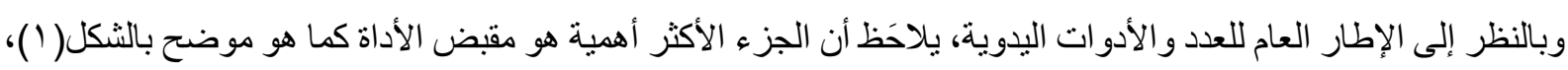
فهى الوسيلة المباشرة التى يتفاعل معها المستخدم ليتمكن من الاستخدام و أداء المهمة المطلوب تنفيذها.

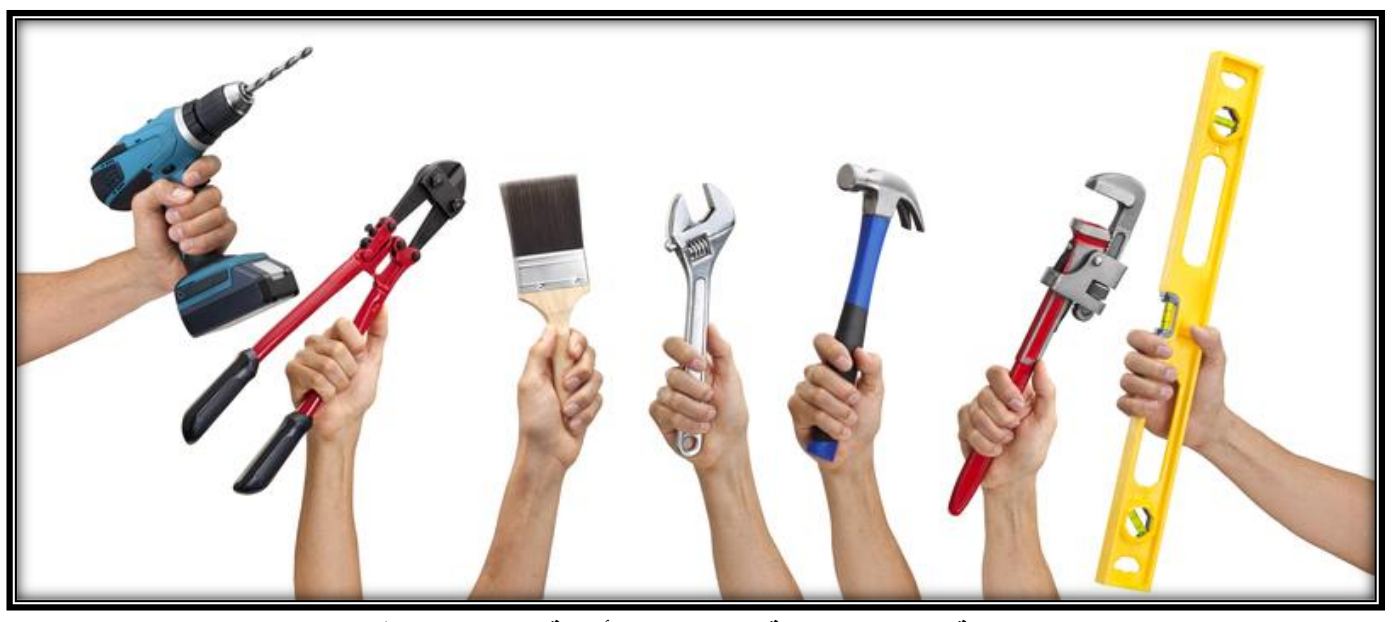

شكل (1) مجموعة من العدد اليدوية والتى توضح أهمية المقبض وعلاقته بالمستخدم

(Source: https://hireitdirect.co.uk/wp-content/uploads/2019/05/Hands-Holding-Tools-23602042.jpg)

لذللك اهتمت الأبحاث و الدر اسات كثيرًا بوضع معايير لتصميم تللك المقابض بما يتناسب مع طبيعة المستخدم و الوظيفة التى تؤديها. ولقد اقتصرت تلك الأبحاث فى البداية على تحديد الأقطار المناسبة للمقابض الأسطو انية، لزيادة الراحة ورفع كفاءة الاستخدام بجانب تقليل فرص الإصابة بما يُعرف بالإصابات الناتجة عن استخدام مقابض تللك العدد و الأدوات، مثل البثور

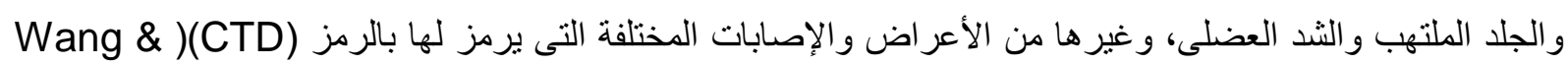

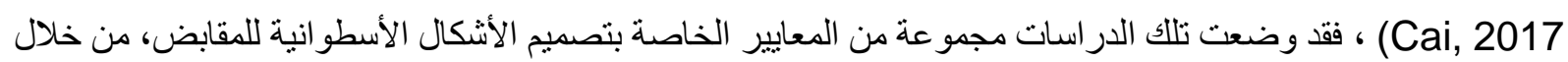
تحديد الحجم و الثكل الأمثل لمقبض الأداة، وهى ملخصة فلى فلى النقاط النالية: • قطر المقبض: تشير الدراسات والأبحاث إلى أنه يجب فى البداية الأخذ فى الاعتبار حركة يد المستخدم عند الإمساك

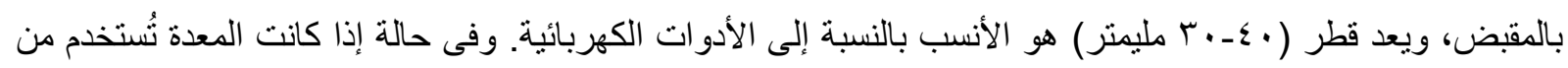

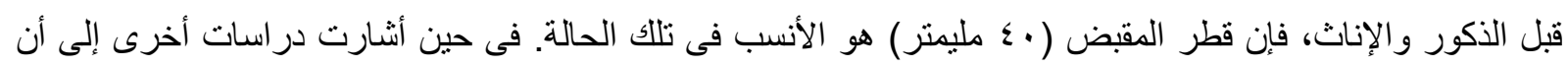

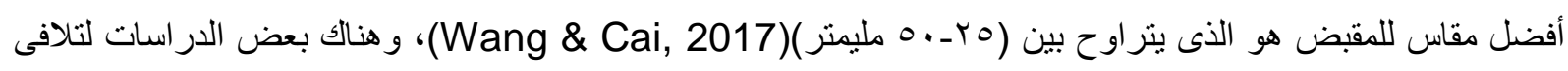

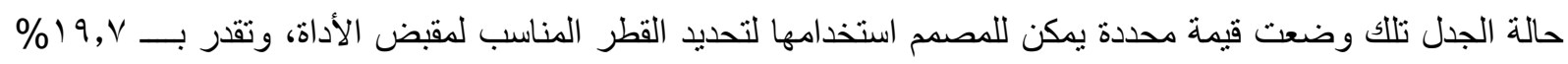
من الطول الكلى للأداة.. Kong \& Lowe, 2005) 
• شكل المقبض: تشير الدراسات و الأبحاث بأن الثكل الأنسب والأفضل للمقبض هو الشكل البيضاوى، حيث تكون نسبة

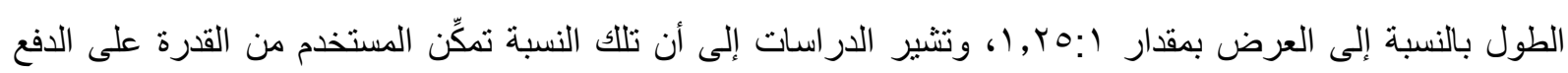

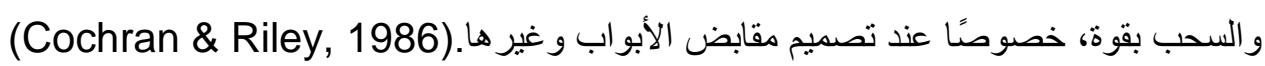

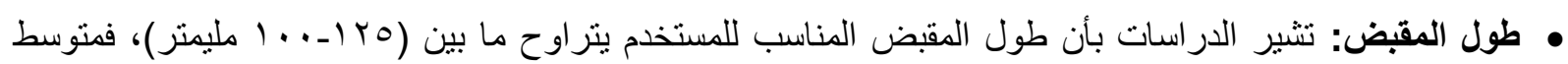

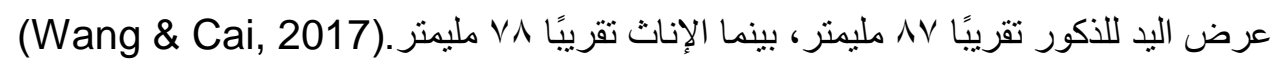

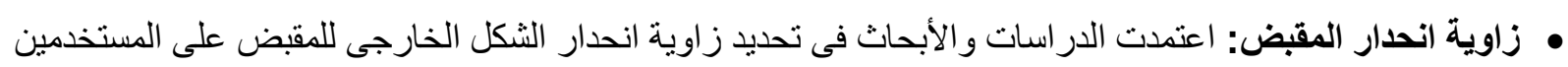
ومدى تفضيلهم للأشكال المستخدمة، فقد وجدت الدراسات أن المستخدمين يفضلون استخدام الأدوات و العدد ذات المقبض المنحدر بزاوية • ا درجات عن القبضات المستقيمة (Controzzi, Cipriani, \& Carrozza, 2014)، فى حين اعتمدت الدراسات الأخرى على دراسة الآثار المترتبة عن استخدام المقبض، وتوصلت إلى أن استخدام زاوية إمالة لتصميم

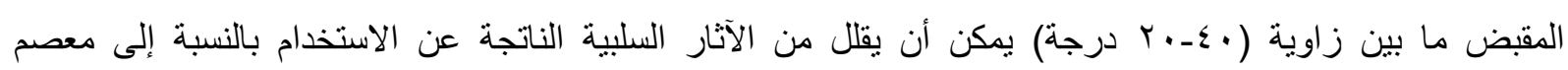

المستخدم.(Schoenmarklin \& Marras, 1989) ولقد انقست الدراسات والأبحاث للوصول إلى المعايير والاشتر اطات إلى قسمين، فى القسم الأول اعتمدت فيه الدراسات والأبحاث على القياسات الإنثروبومترية المرتبطة بالمستخدم لإيجاد العلاقة الصحيحة و المناسبة بين بد المستخدم و الأداة، من خلال وضع مجمو عة من المحددات حتى يمكن التوصل إلى سهولة القياس و المقارنة و الاستنتاج. فعلى سبيل المثال، فى لئ

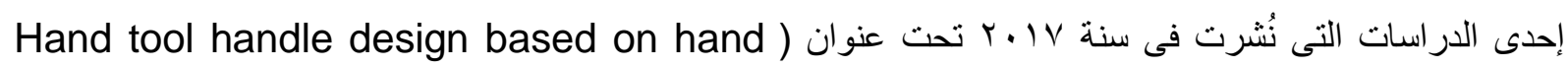

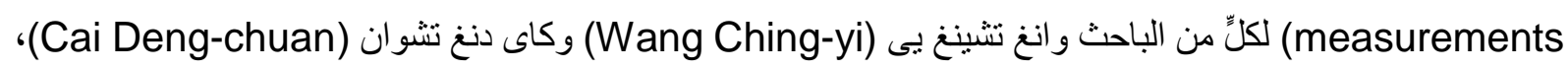
فقد اعتمدت دراستهما على القياسات الإنثروبومترية، مع وضع محددات لسهولة القياس كما هو موضح بالثكل (Y)، ثم

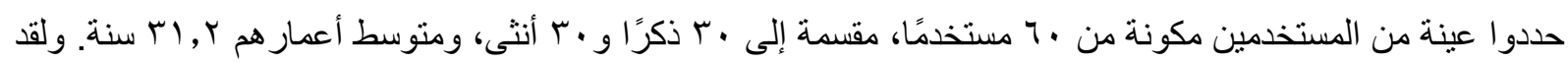

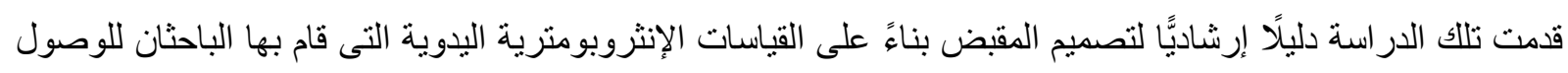
إلى معايير إرشادية تساعد المصممين على الوصول إلى تصميم أفضل لمقبض الأداة المستخدمة من قبل المستخدمين.

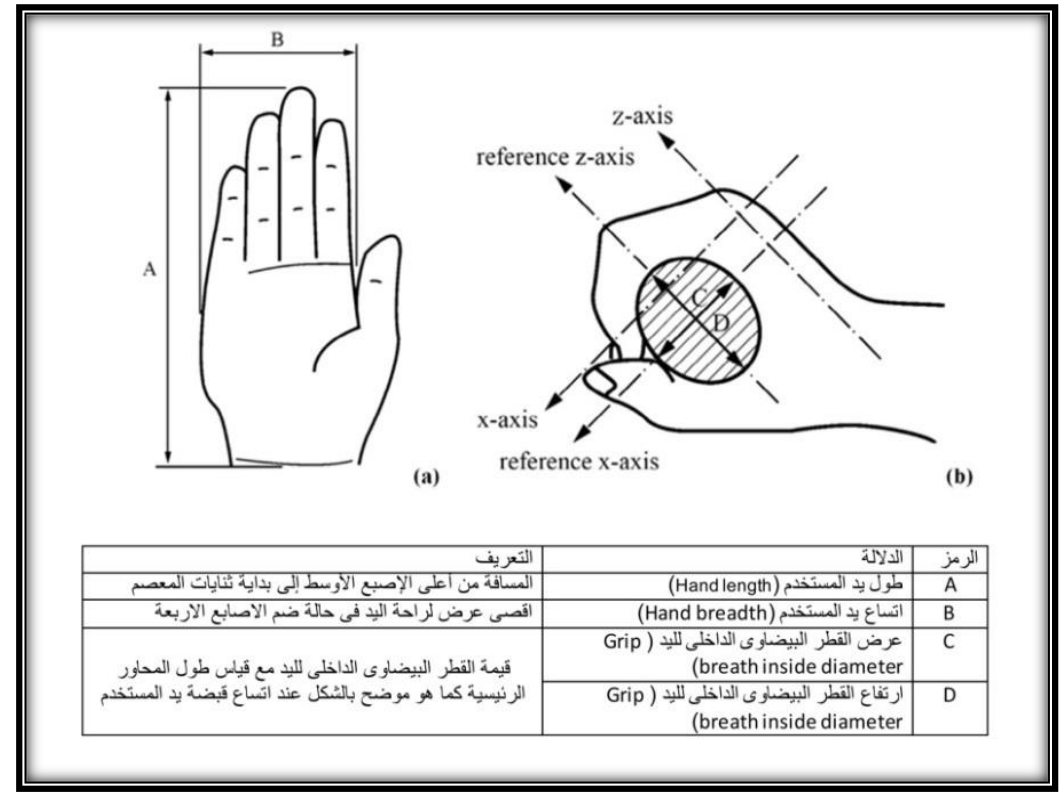

شكل (Y) تحديد محدات لإمكانية القياس و المقارنة من قبل الباحثين (Wang \& Cai, 2017) 
بينما القسم الثانى اعتمدت فيه الدر اسات والأبحاث على تحليل العلاقة التفاعلية والمباشرة بين المستخدم والأداة. فقد توصلت تللك الدر اسات إلى أن هنالك علاقة مبانثرة بين وضعية شكل يد المستخدم التى تتخذ وضعية ما نتيجة لتصميم مقبض الأداة، و الآثار المترتبة على عملية الاستخدام، فقد توصلت الدراسات إلى أن الوضعيات غير الملائمة لطبيعة الاستخدام تنتج عنها مضاعفات كثيرة، وتؤثر على نحو مباشر أو غير مباشر فى المستخدم، ما دفع كثيرًا من الدراسات والأبحاث إلى تحليل

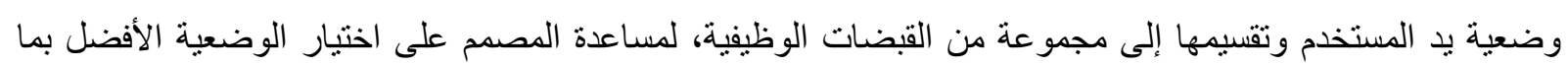
يتناسب مع طبيعة الوظيفة المطلوب تتفيذها بواسطة الأداة. فعلى سبيل المثال فى دراسة بعنوان ( The GRASP (Taxonomy of Human Grasp Types the European ) وخافيير روميرو (Thomas Feix) (Commission )، واستهدفت نللك الدراسة الوصول إلى أكبر مجموعة من القبضات و الوضعيات المختلفة لبد المستخدم (1homas نتيجة لاستخدام المنتجات اليومية، و إعادة ترتيبها بطريقة منهجية تمكن الاستفادة منها من قبل الباحثين و المصممين. ولقد اعتمدت تلك الدر اسة على مجموعة من المعايير، من أهمها مقدار القوة المبذولة من قبل المستخدم، والدقة المطلوبة لأداء

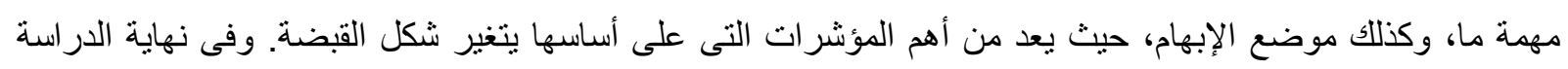

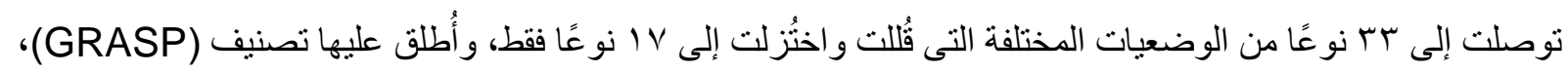

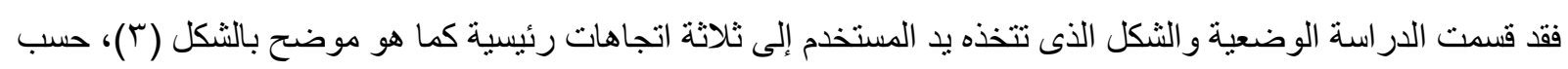

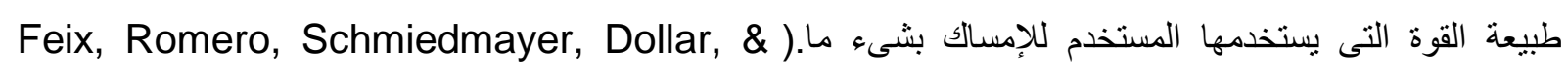

(Kragic, 2015

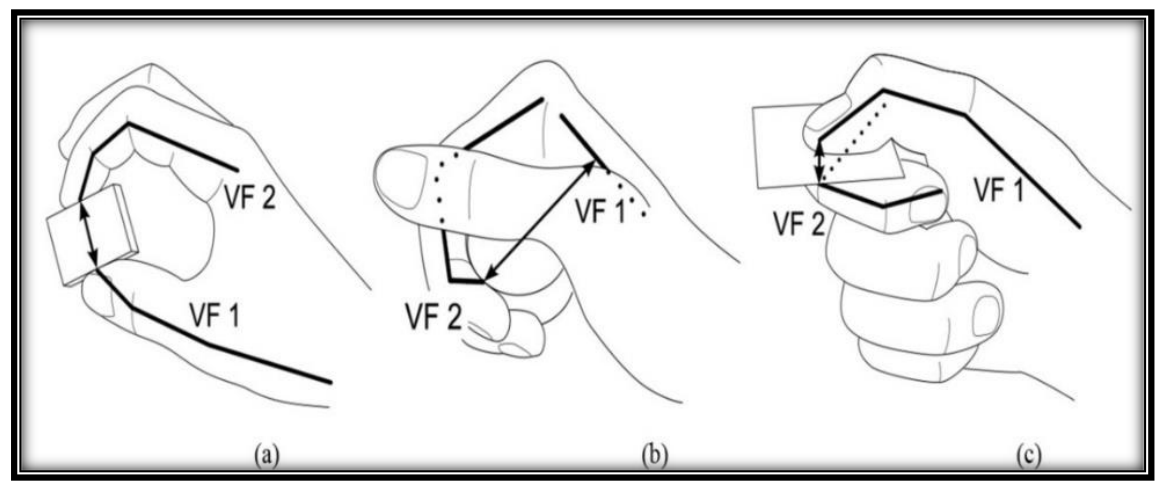

شكل (ّ) الاتجاهات الثلاثة الرئيسية التى تتخذها يد المستخذم حسب طبيعة القوة المستخدة (Feix et al., 2015)

Pencil grip. A ) أيضًا من الدر اسات المهمة التى تناولت تحليل وضعية يد المستخدم عند استخدام الأداة دراسة بعنوان (descriptive model and four empirical studies بأن يد المستخدم يمكن أن تتخذ عدة أثنكال ووضعيات مختلفة لنفس الأداة. على سبيل المثال وضعية بد المستخدم عند استخدام قلم الرصاص، فقد وجدت الباحثة بعد مر اجعة لعدد كبير من المستخدمين وجود وضعيات مختلفة عند استخدام نفس لأس الأداة كما هو موضح بالثكل (ع)، بعض منها صحيح و الآخر قد تترتب عليه مشكلات كبيرة للمستخدم. 


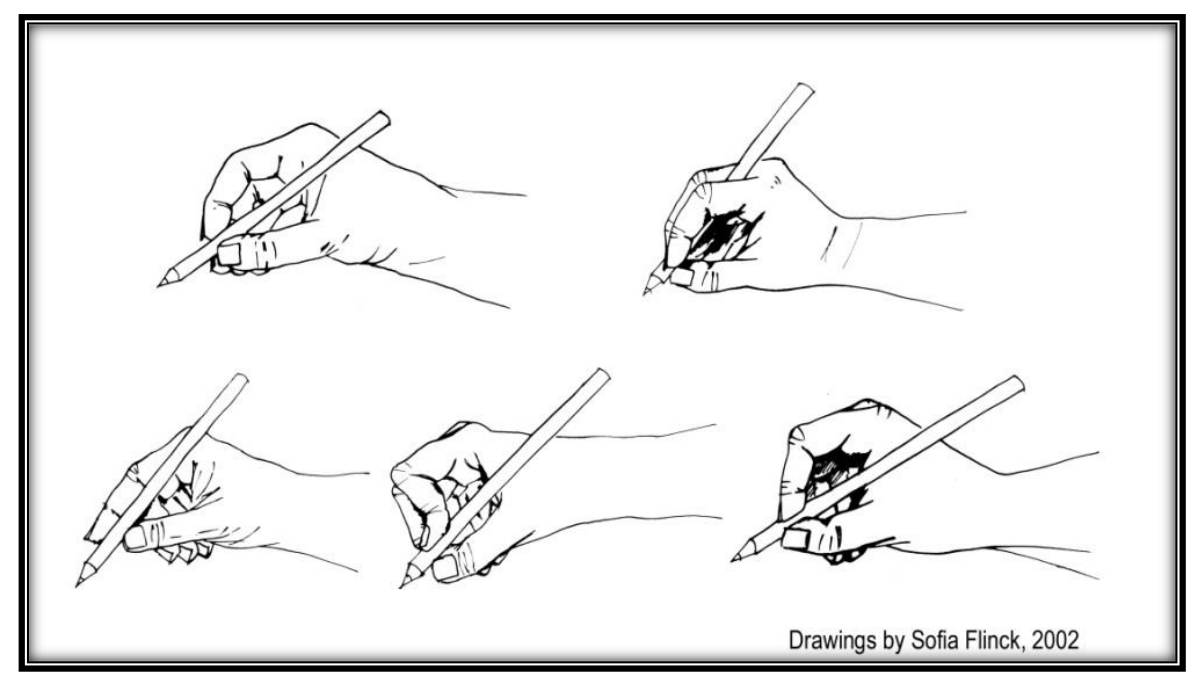

شكل (؛ ) وضعيات مختلفة ليد المستخام عذد استخدام القلم الرصاص (Selin, 2003)

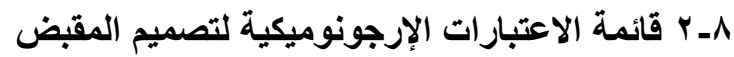
اهتمت الدر اسات والأبحاث منذ ظهور علم الإرجونوميكس بونيكة بوضع قائمة بالاعتبار ات الإرجونوميكية، لتكون بمثابة نقاط إرشادية لمساعدة المصمين على تصميم القبضات الوظيفية بما يلاءم طبيعة المستخدم. و لأن علم الإرجونوميكس من العلوم التر اكمية التى تخضع للتعديل والتجريب، يلاحَظ أن الدر اسات و الأبحاث دائمًا تنظر فى مر اجعة المتطلبات التى وضعتها

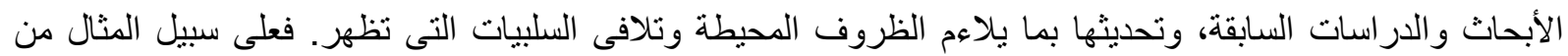

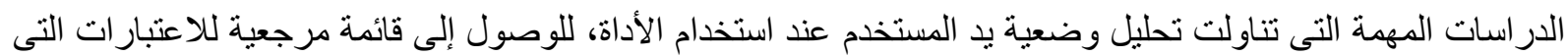

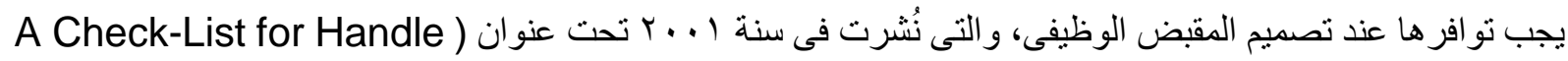
(Design بدأ نشر ها فى عام 1979 بأسنر اليا من خلال ورش العمل الجراحية التى عُققت فى سيدني، ثم أُعيد النظر بها وتطوير ها

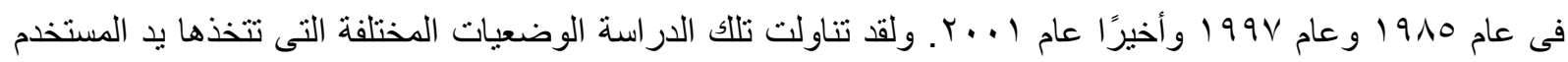
وفق الطاقة المبذولة وشكل الأداة، ثم انتهت إلى وضع قائمة مرجعية يمكن للمصمم الاستعانة بها لتصميم المقابض الوظيفية

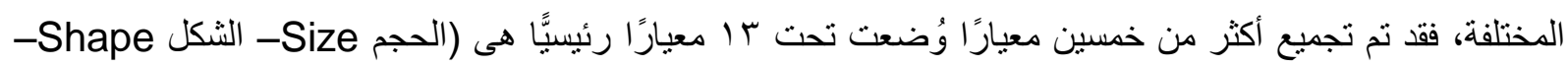
السطح Surface- جوانب الأمان Security- الصلابة Stiffness- الموقع Siting- العناصر المحيطة

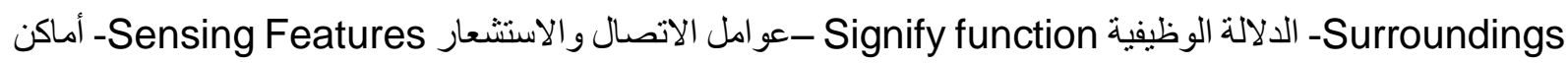
Skill مهار ات خاصة مطلوبة من المستخدم Special other features عو امل أخرى خاصة -Storage التخزين

Needed التأكد من مدى ملائمة التصميم Validating design). أيضًا من الأبحاث المهمة التى سعت للوصول إلى قائمة مرجعية تساعد المصمين عند تصميم المقابض الوظيفية بحث بعنوان (A Checklist for the Ergonomic Evaluation of Non-powered Hand Tools) للباحث عو اد دبابنة من جامعة الأردن، والباحث بريان لوى (Brian Lowe)، والباحث إد كريج (Ed Krieg)، والباحث يونج كو

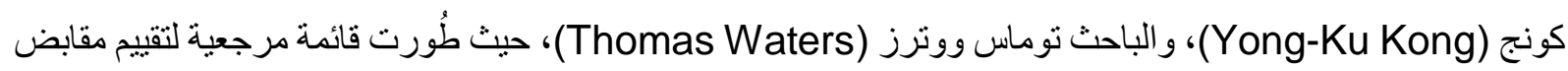
الأدوات اليدوية غير المزودة بالطاقة من خلال 17 عنصرًا رئيسيَّا، واختير عدد 1 ا أداة يدوية نموذجية وحُددت عينة من

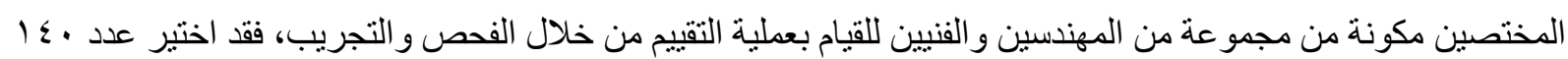




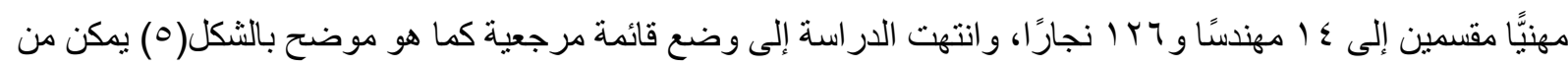
خلالها مساعدة المصممين على الوصول تصميم أكثر راحة و أمان للمستخدم.

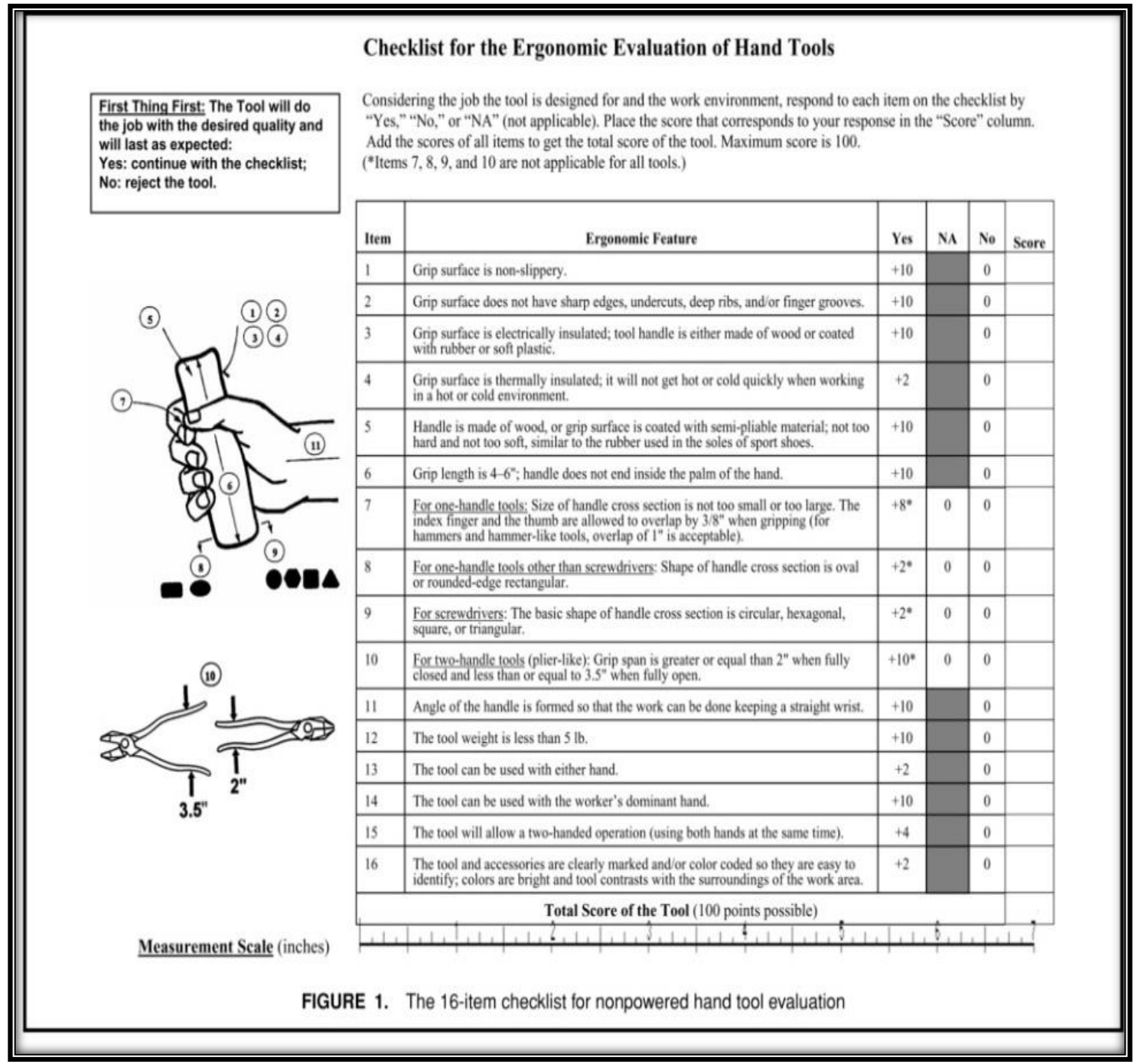

شكل (•) قائمة مرجعية لتقييم الادوات اليدوية الغير مزودة بالطاقة (Dababneh, Lowe, Krieg, Kong, \& Waters, 2004)

و فيما يلى جدول ( (1) يستعرض باختصار النقاط الرئيسية التى اعتمدت عليها الدراسات للوصول إلى وضع قائمة مرجعية للاعتبار ات الو اجب تو افرها عند تصميم المقابض الوظيفية بالمنتجات الصناعية.

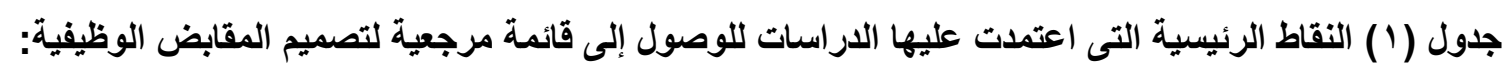

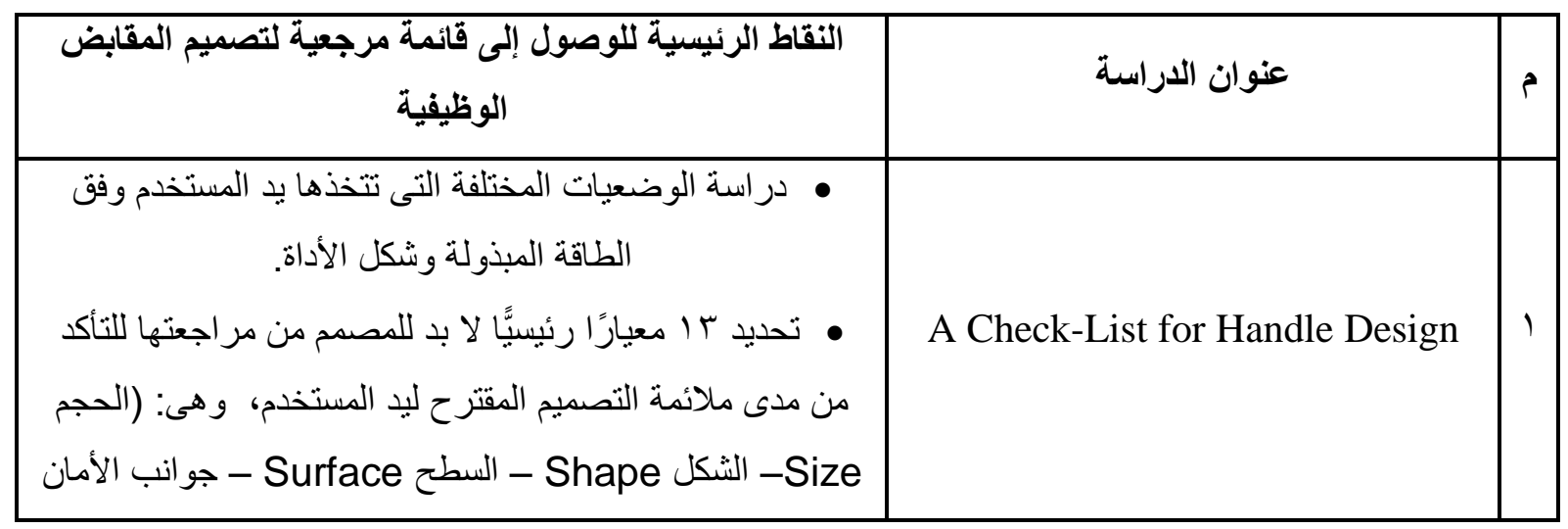




\begin{tabular}{|c|c|}
\hline 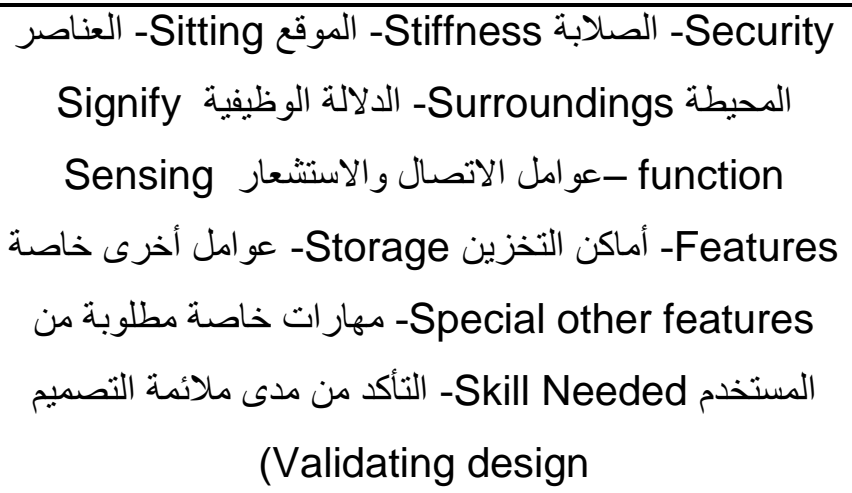 & \\
\hline 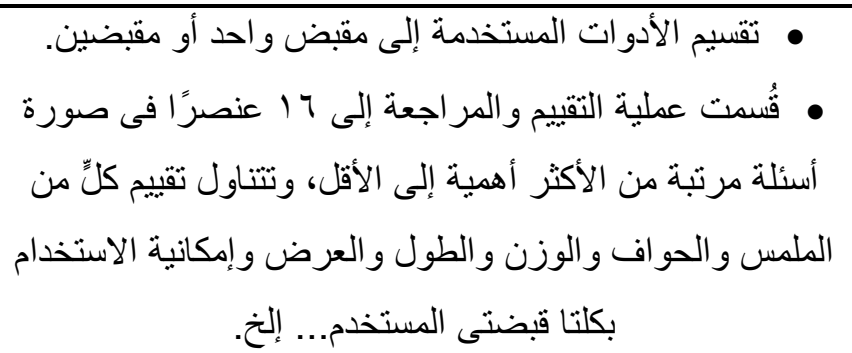 & $\begin{array}{c}\text { A Checklist for the Ergonomic } \\
\text { Evaluation of Non-powered Hand } \\
\text { Tools }\end{array}$ \\
\hline
\end{tabular}

ويمراجعة الدراسات والأبحاث السابقة من قبل الباحث للوصول إلى وضع قائمة مرجعية للاعتبارات الواجب مراعاتها

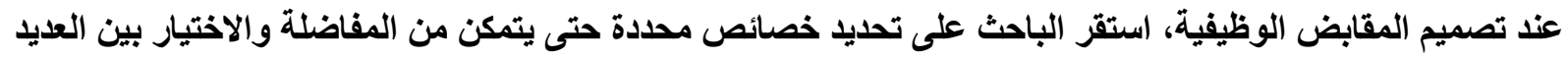

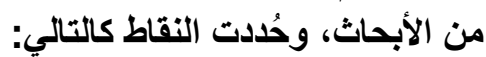

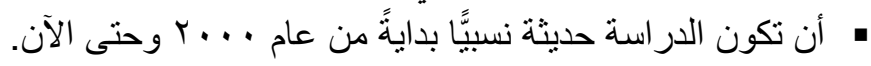

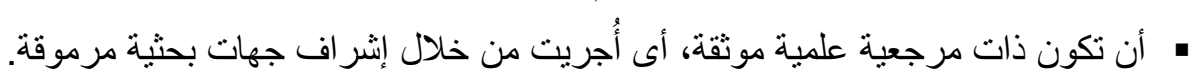
• أن تكون استكمالًا لدر اسات و أبحاث سابقة. وبمراجعة عديد من الدراسات والأبحاث، حدد الباحث أربع دراسات كمرجعية نساعده على تحديد الاعتبارات، وتلكلك الدر اسات هى:

A Checklist for the Ergonomic Evaluation of Non-powered Hand ) الدراسة الأولى بعنوان

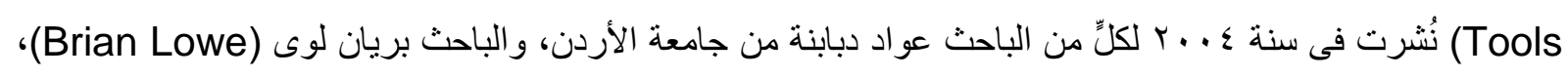

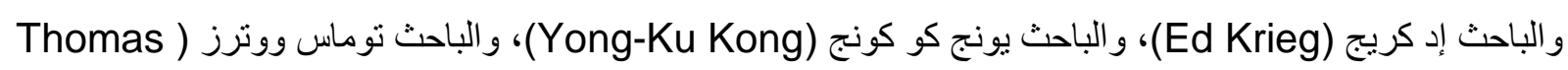

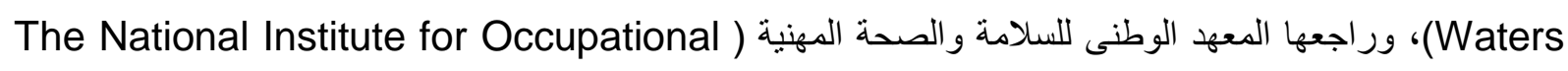

.(Safety and Health

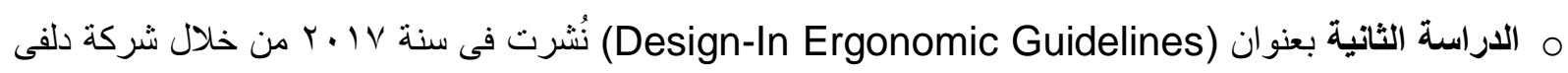
بالمملكة المتحدة كمرجعية علمية يمكن الاعتماد عليها عند تصميم المنتجات الصناعية المختلفة ومنها العدد اليدوية. م الدراسة الثالثة بعنوان (Hand tool handle design based on hand measurements) نُشرت في عام

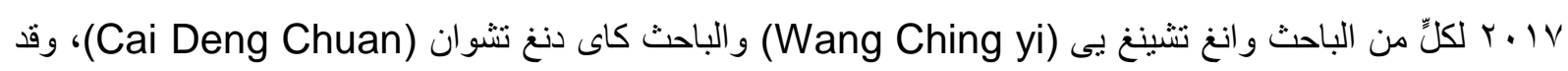
أُعدت بالتعاون بين قسم التصميم الصناعى بجامعة تاتونج (Tatung University) وجامعة يونلين الوطنية للعلوم و التكنولوجيا (National Yunlin University of Science and Technology) بتايو ان. 
م الاراسة الرابعة بعنوان (A Check-List for Handle Design) نُشرت فى سنة ا. . Y للباحث مايكل باتكين (Michael Patkin)

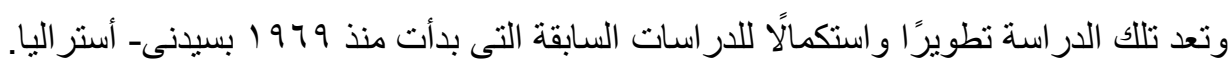
وبدر اسة الدراسات والأبحاث السابقة وضع الباحث قائمة مرجعية لتصميم المقابض الوظيفية من قبل الباحث تتكون من (ثلاثة مر احل) كما هو موضح بالثكل (ال)

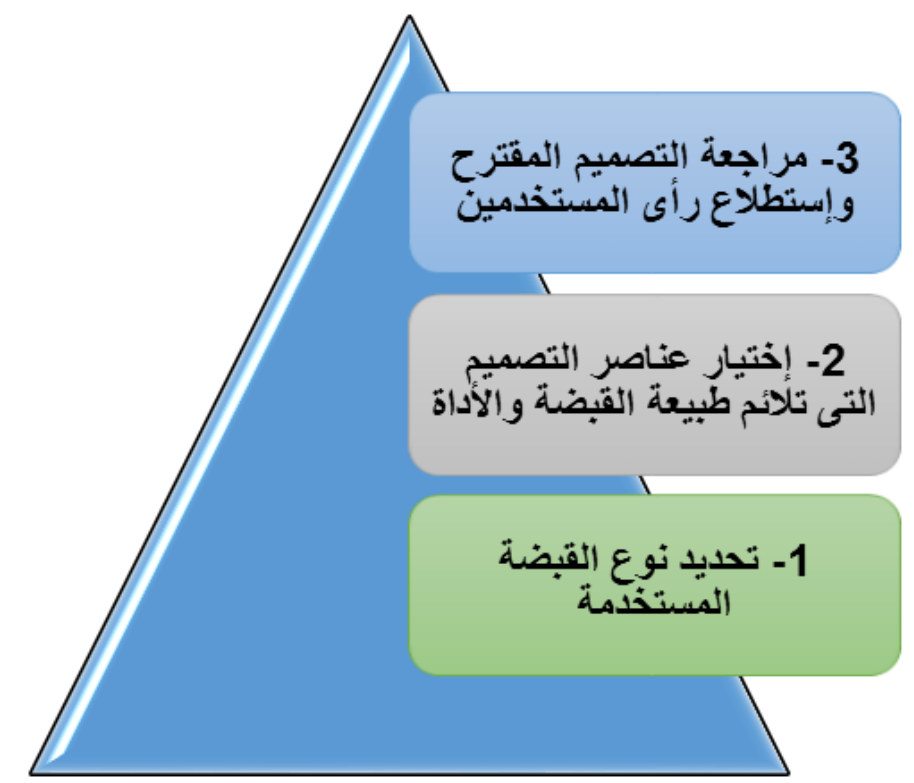

شكل (آ) شكل مقترح لمراحل عملية التصميم المقترحة لتطبيق معايير تصميم المقابض الوظيفية

وفيما يلى استعراض لمراحل عملية التصميم المقترحة:

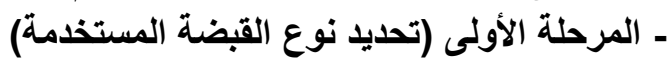
من الضرورى للمصمم تحديد نوع القبضة المستخدمة من قبل المستخدم للأداة، حتى يتسنى لله الانتقال إلى المرحلة الثانية و الاختبار بين الاشتراطات و المقاسات المقترحة من قبل الباحثين التى تتاسب القبضة المستخدمة. ووفق الدراسات السابقة يمكن تقسيم نوع القبضة إلى نوعين أساسيين هما: • قبضة القوة (Power grip): وهى القبضة التى تتجمع أصابع المستخدم بإحكام حول جسم ما وتتداخل مع الإبهام، وتُشتخدم عادةً مع الأدوات اليدوية التى تحتاج إلى قوة فئ الاستخدام. • قبضة الإحكام (precision grip): و هى القبضة النى يتم استخدام كلٍّ من الإبهام و السبابة و الوسطى، ولادئ ولا تتطلب

استخدام قوة كبيرة، وتُستخدم عادةً لالتقاط الأشياء الصغيرة أو فى الأعمال الفنية. (Patkin, 2001) ينقسم كلّ من النوعين السابقين إلى مجموعة من القبضات المختلفة، ولكن الأصل هو إما قبضة قوة و إما قبضة إحكام.

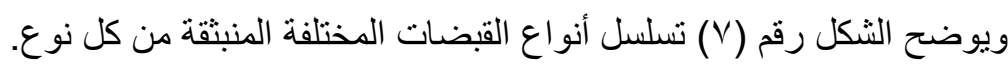




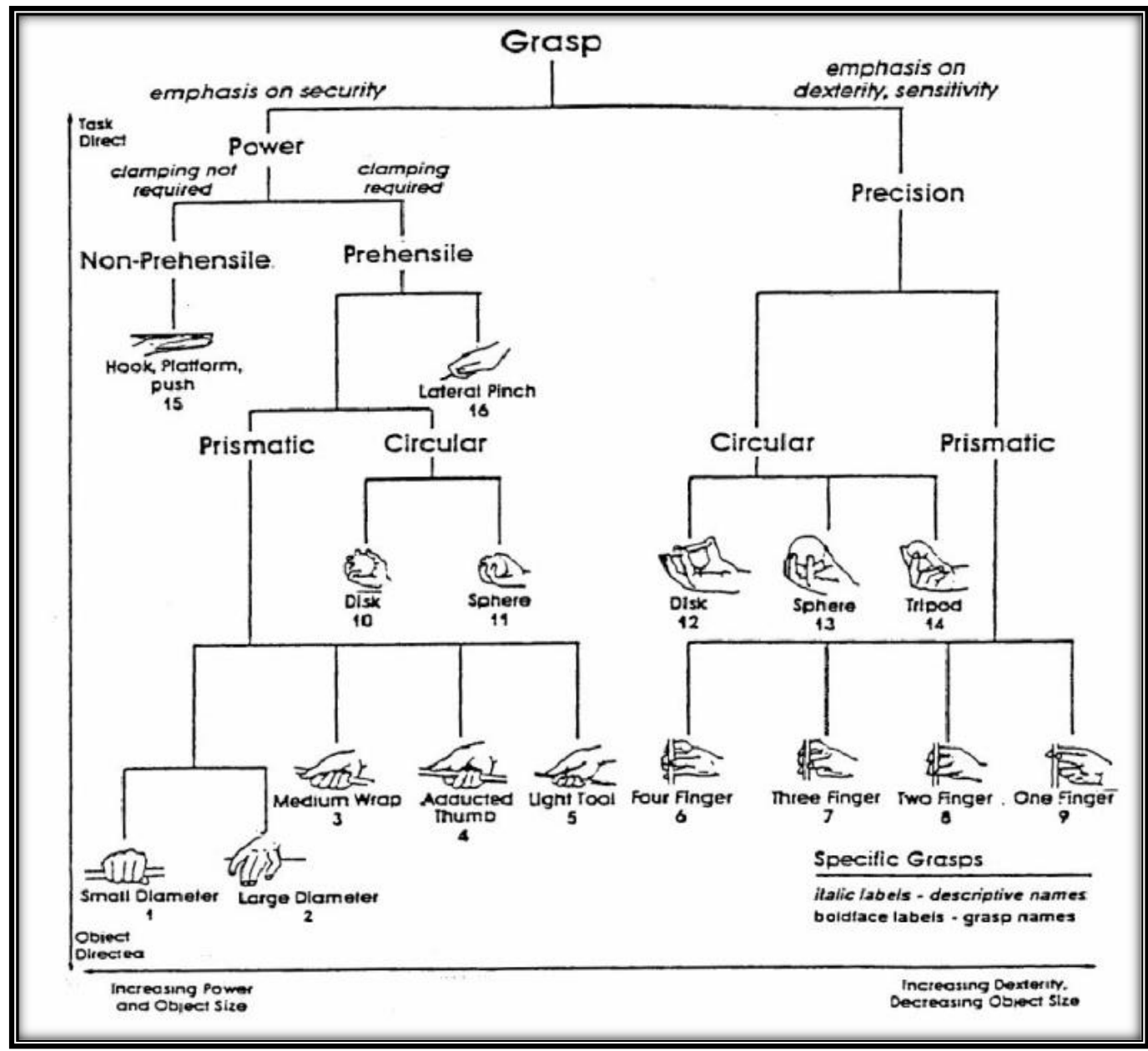

شكل (Vontrozzi et al., 2014) cutkosky and howe's تصنيف القبضات المختلفة حسب تصنيف كلّ" من

ـ المرحلة الثانية (اختيار عناصر التصميم التى تلاؤم طبيعة القبضة والأداة)

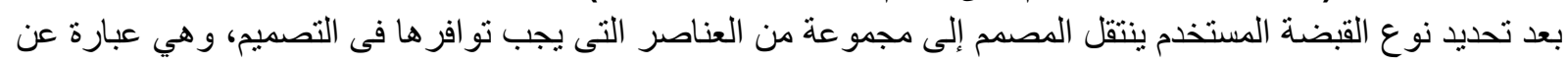
(الثكلـ الطول ـ الوزن- طبيعة السطح - عو امل الأمان- الدلائل الوظيفية وعو امل الاتصال) كما هو موضح بالجدول

جدول (r): العناصر التى يجب توافرها فى تصميم المقابض اليدوية

\begin{tabular}{|c|c|c|c|}
\hline $\begin{array}{c}\text { قبضة الإحكام } \\
\text { precision grip }\end{array}$ & \multicolumn{2}{|c|}{$\begin{array}{c}\text { قبضة القوة } \\
\text { Power grip }\end{array}$} & العنصر \\
\hline 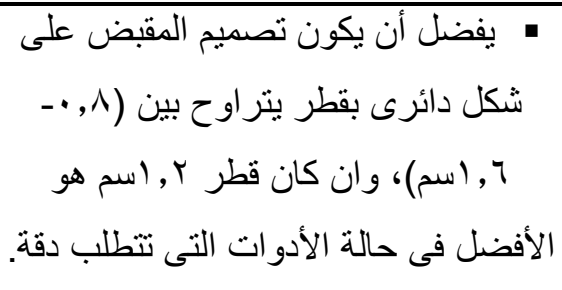 & \multicolumn{2}{|c|}{ 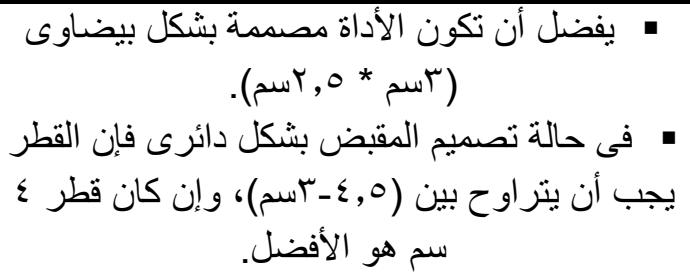 } & \multirow{2}{*}{ الثكل } \\
\hline 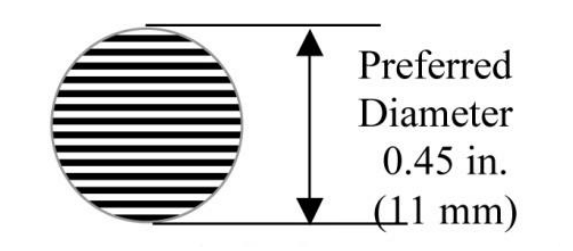 & (2.5 cm) & 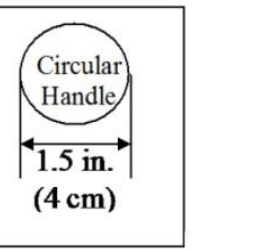 & \\
\hline
\end{tabular}




\begin{tabular}{|c|c|}
\hline الحد الأدنى لطول المقبض للأداة اليدوية يجب ألا يقل عن · ا سم، و إن كان طول المقبض 10 & الطول \\
\hline 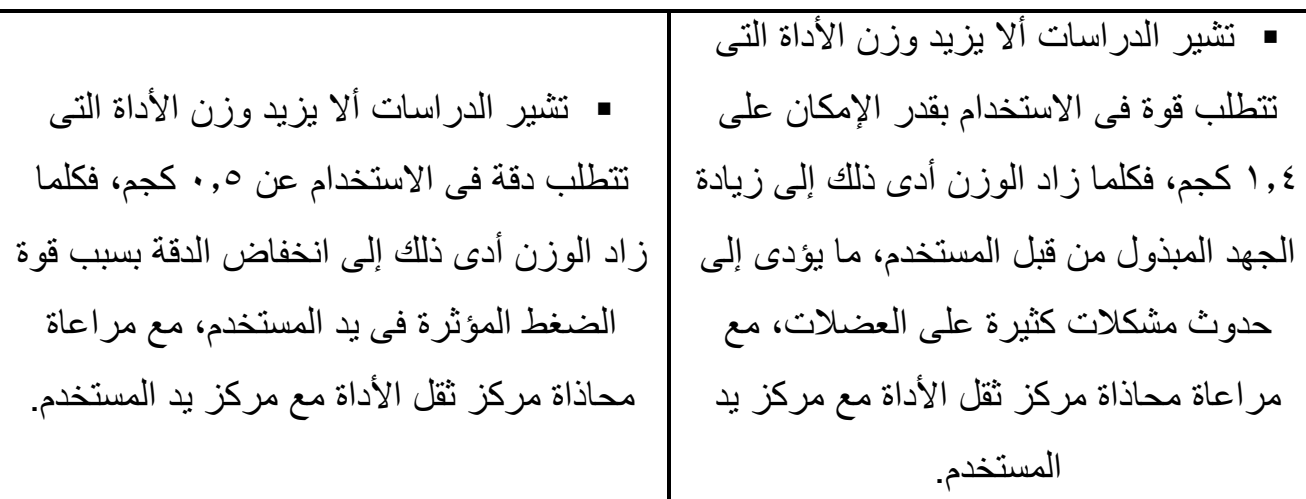 & الوزن \\
\hline 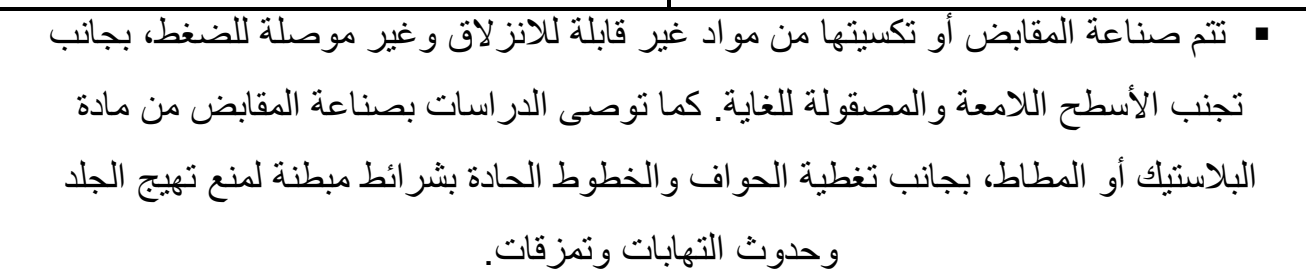 & طبيعة السطح \\
\hline 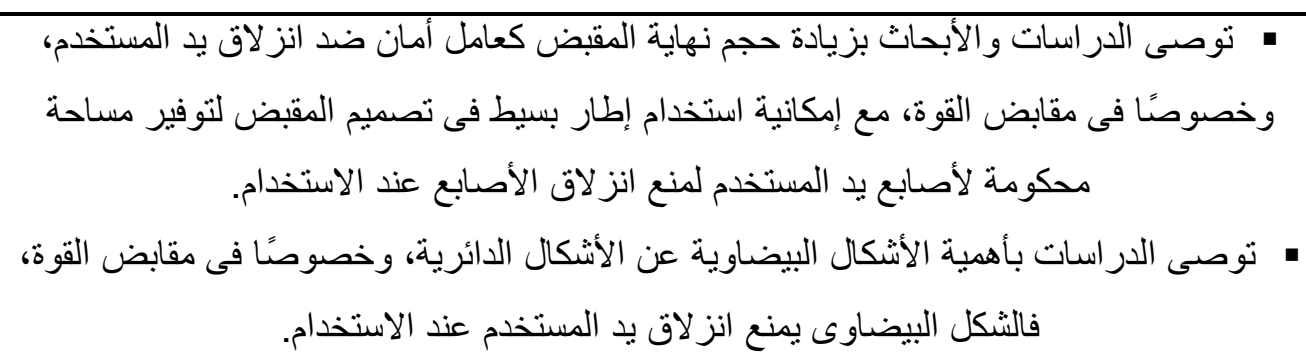 & عوامل الأمـان \\
\hline 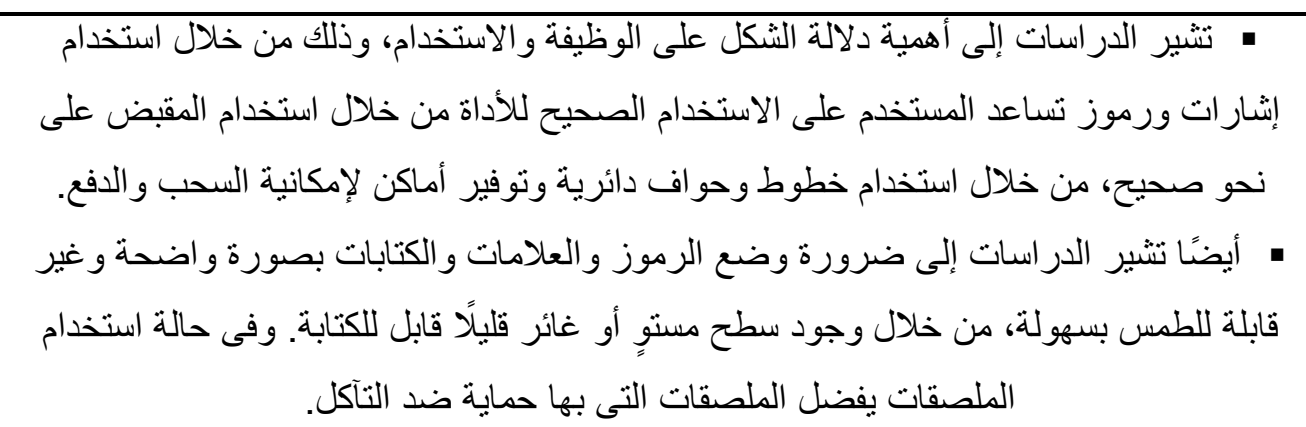 & وعوامل الاتصل الوظية \\
\hline
\end{tabular}

ـ المرحلة الثالثة (مراجعة التصميم المقترح واستطلاع رأى المستخدمين)

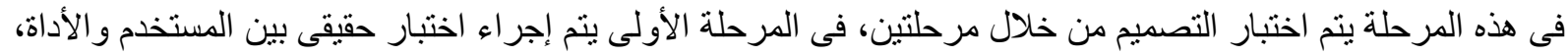

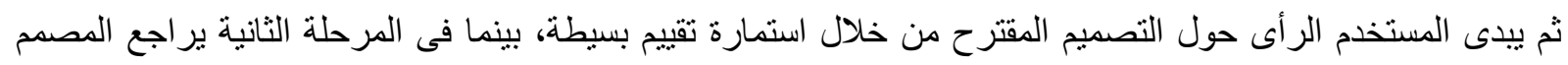

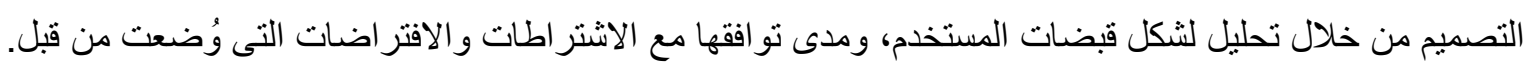


ومن خلال الدر اسات السابقة أعد الباحث استمارة تقييم يمكن من خلالها تقييم التصميم من قبل المستخدمين والتعرف على تلى آرائهم، التى يمكنها أن تساعد المصمم على تحسين وتطوير التصميم المقترح ونلافى المشكلات المختلفة به، حيث نعتمد

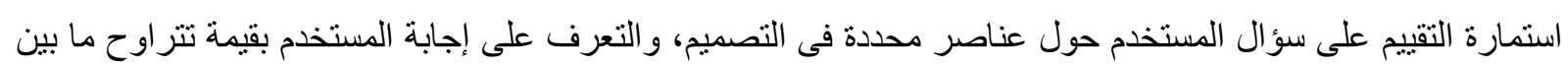

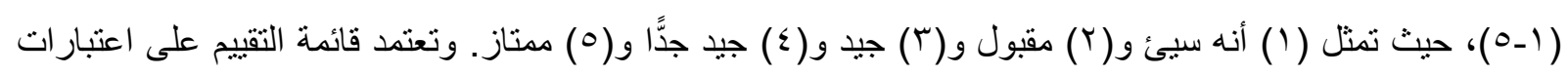

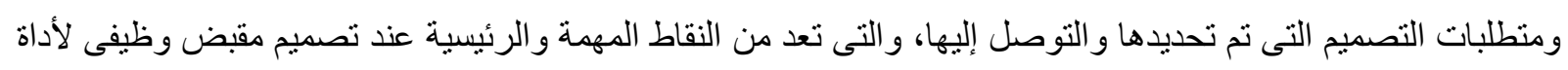
يدوية، وبذلك يمكن للمصمم تحديد أوجه الخطأ فى أى عنصر من العناصر و العمل على تطويره و الثكل رقم (^) يوضح صورة لتصميم استمارة التقييم المستخدمة.

\begin{tabular}{|c|c|c|c|c|c|}
\hline \multicolumn{4}{|c|}{ التقييم } & \multirow{2}{*}{ 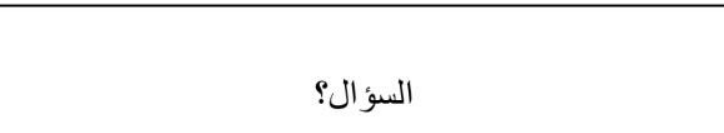 } & \multirow{2}{*}{ s } \\
\hline 0 & $\varepsilon$ & $\bar{r}$ & r & & \\
\hline & & & & هل تثعر بالر احةٌ عند استخدام المقبض؟ & 1 \\
\hline & & & & هل طول المقبض يتناسب مع طبيعة يدك؟ & $r$ \\
\hline & & & & هل وزن المقبض مناسب للاستخدام؟ & $r$ \\
\hline & & & & هل طبيعة سطح وملمس المقبض تتناسب مع الاستخدام؟ & $\varepsilon$ \\
\hline & & & & هل أنت راضى عن جوانب الامان عند استخدام المقبض؟ & 0 \\
\hline & & & & هل العلامات الارشادية بالمقبض واضحة وسهلةّة الفهج؟ & 7 \\
\hline
\end{tabular}

شكل (^) استمارة تقييم التصميم من قبل المستخدمين والتعرف على ارآتهم

A-r تطبيق قائمة الاعتبارات الإرجونوميكية لتصميم المقبض مع طلبة التصميم الصناعي

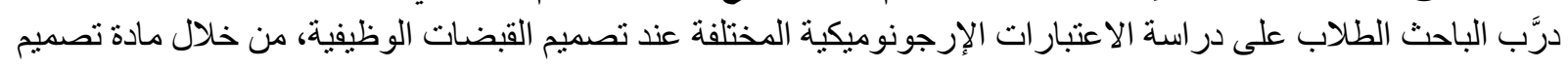

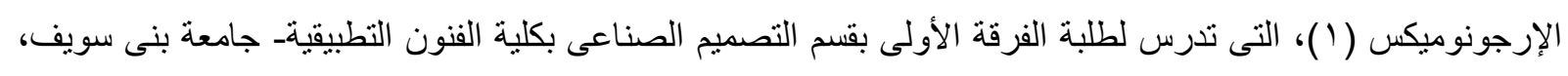

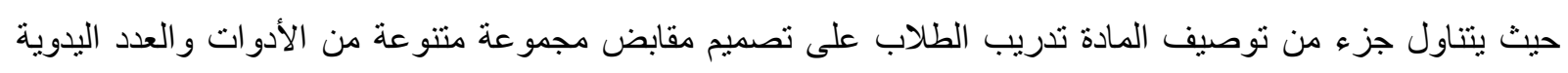

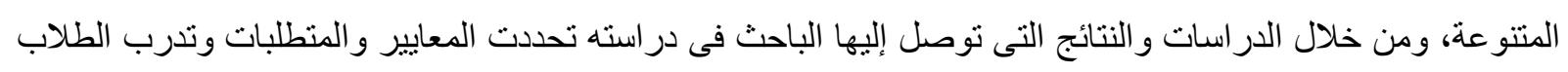

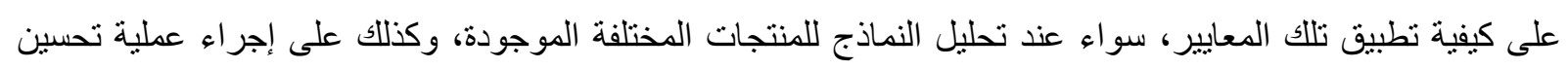

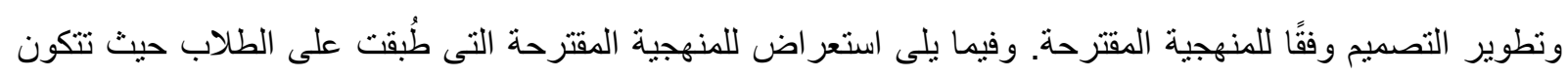

المنهجية كما هو موضح بالثكل (9).

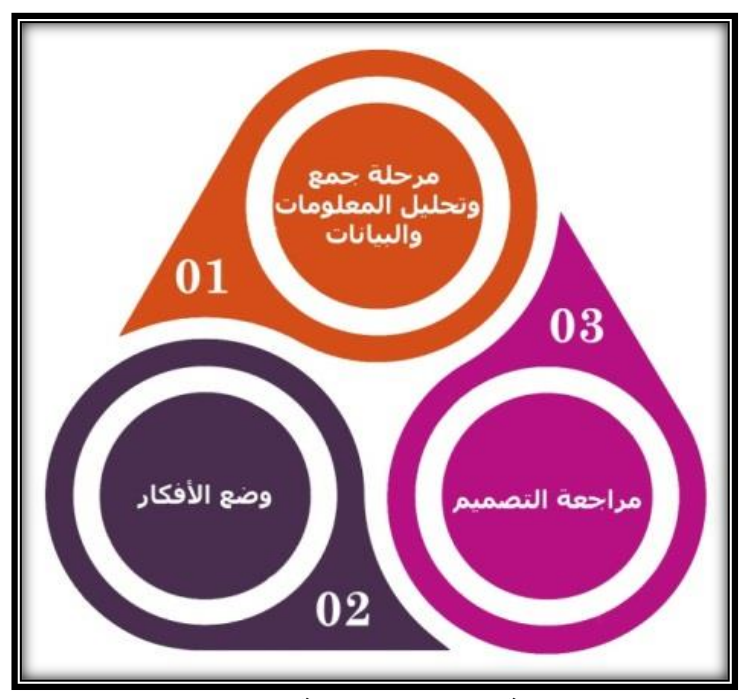

شكل (9) شكل مقترح لمراحل عملية التصميم المقترحة لتطبيق معايير تصميم المقابض الوظيفية 


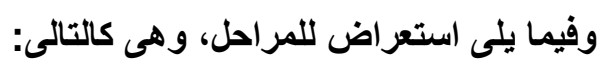

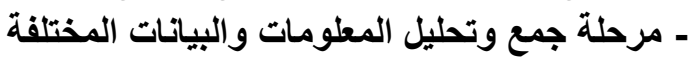

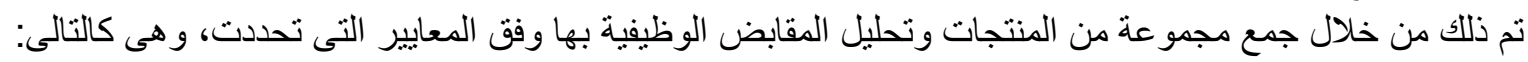
• تحديد نوع القبضة المستخدمة من قبل المستخدم.

• مر اجعة للمقاسات الهندسية للمقبض من حيث الطول و الحجم و الثكل. • مر اجعة جو انب الأمان من خلال التعرف على طبيعة السطح ومدى ملاءمته ليد المستخدم، وعو امل الأمان الأخرى. • تحديد مجموعة من المميزات و العيوب للمقبض حسب اعتبارات التصميم الأساسية، مثل (الناحية الوظيفيةـ

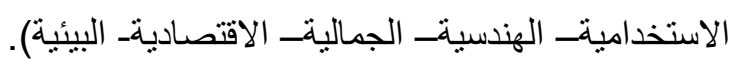

• وضع مقترحات للتطوير، وتعد بمثابة نقاط استرشادية للطلاب تمكنه العودة إليها فى حالة نطوير التصميه. ومن خلال ما سبق حُللت مجمو عة متنو عة من المنتجات، لتحديد أوجه القصور وتحديد المشكلات الإرجونوميكية التى يمكن

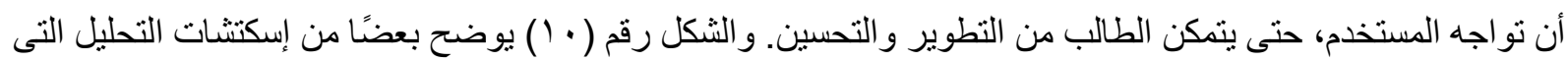
قام بها الطلاب من تحليل لمنتجات قائمة من خلال القائمة المرجعية التى تحددت سابقًا.
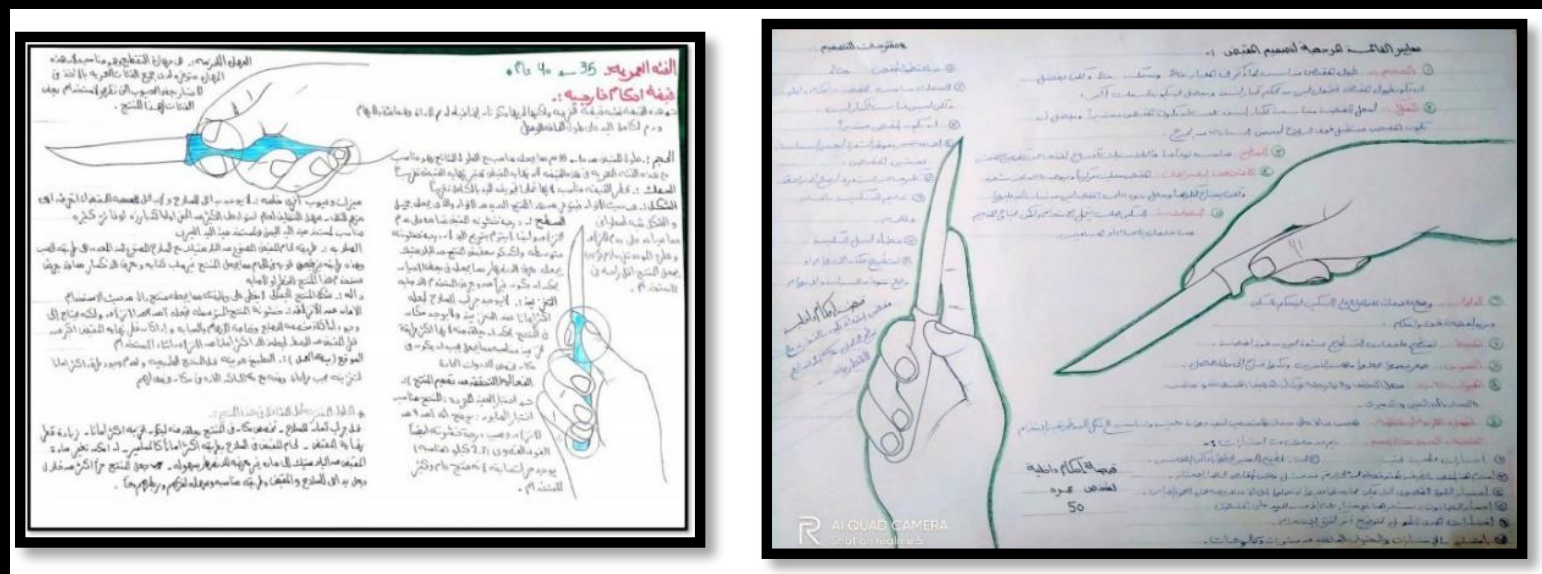

الطلبة/ إيمان محمد إبراهيم

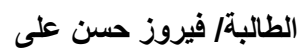

شُكل ( • 1) نموذج من إسكتشات تحليل المنتجات من خلال الطلاب

\section{- مرحلة وضع الأفكار}

بعد تحليل المنتجات المختلفة وضع الطلاب مجموعة من الأفكار، مع مر اعاة المنطلبات الإرجونوميكية التى حُددت سابقًا

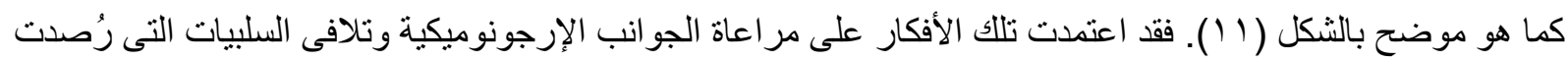
بمرحلة تحليل المنتجات المختلفة، بجانب وضع المتطلبات الرئيسية لتصميم المقابض من ضمن الاشتر اطات الأساسية فى الإسى متطلبات التصميم الواجب تحقيقها فى الفكرة المقترحة. 


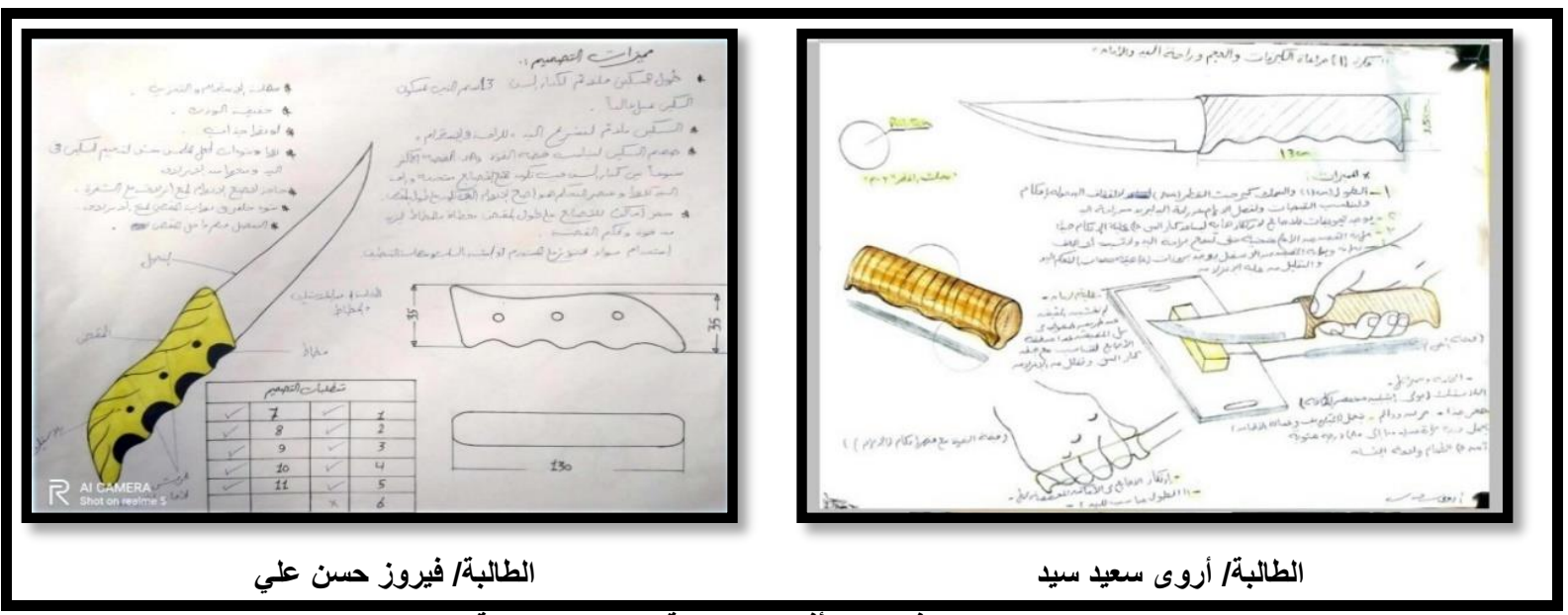

شكل (1' (') نموذج من الأفكار المقترحة للمقابض اليلوية

- مرحلة مراجعة التصميم

فى هذه المرحلة يحول الطالب التصميم إلى نموذج مادى يمكن استخدامه واختباره، حيث يعرض الطالب التصميم على هرئ مجمو عة من المستخدمين، ثم يصور الأوضاع الاستخدامية المختلفة لكل مستخدم، ثم يحللهاو وفق التحليل الذى انُّع بالمرحلة الأولى، مرحلة تحليل المعلومات و البيانات، كما هو موضح بالثكل ( r ( ) للتأكد من مدى ملائمة التصميم للمستخدم، وكذلك

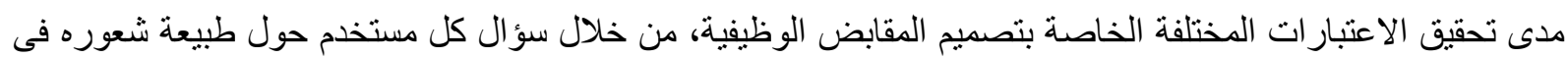
أثناء الاستخدام وتأثير ملمس السطح عليه... الخ، وفق نموذج التقييم الذى صممه الباحث.

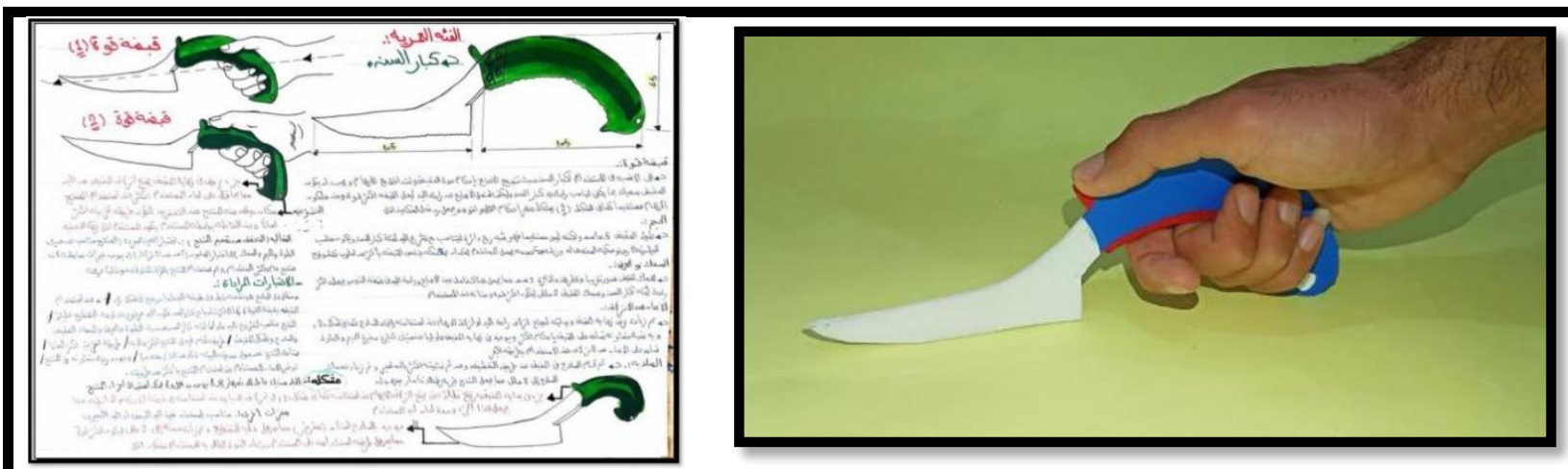

الطالبة/ إيمان محمد إبراهيم

شكل (Y I ) نموذج من الفكرة النهائية وإسكتش التحليل الخاص بمراجعة المتطلبات الإرجونوميكية

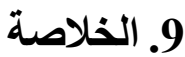

يهنم علم الإرجونوميكس بتحسين تجربة الأداء بين المستخدم والمنتج، وتحقيق أقصى معايير الراحة والأمان فى أثناء الاستخدام، لذلك أُطلق على هذا العلم "فن التصميم لر احة ورفاهية المستخدمين". وبالنظر إلى طبيعة المنتجات الصناعية

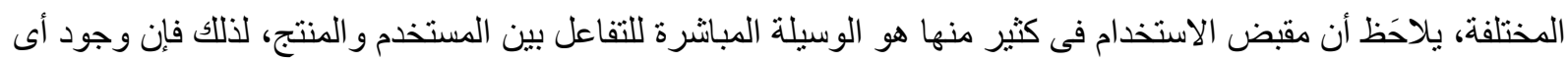

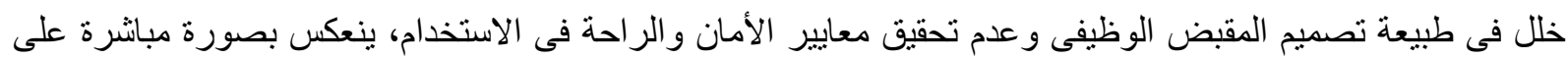

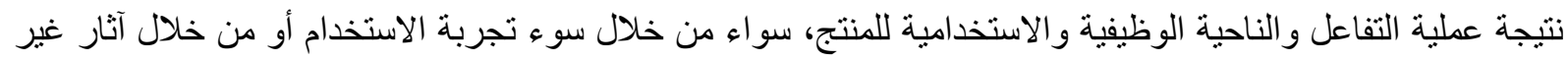
مباثرة، منمثلة فى إحداث مشكلات جسمانية و عضلية للمستخدم على المدى البعيد. لذلك اهتمت المؤسسات و الأكاديميات بالبحث عن معايير محددة يمكن للمصمم الاستفادة منها عند تصميم تللك المقابض الوظيفية، وتلافى الآثار المترتبة عن تللك العملية فى المستقبل. ومن خلال هذا البحث اتبع الباحث المنهج الوصفى التحليلى، من خلال تحليل مجموعة من الدراسات 
و الأبحاث لتحديد مجمو عة من المتطلبات الواجب تو افرها عند تصميم المقابض الوظيفية، وقد وضع الباحث مجموعة من

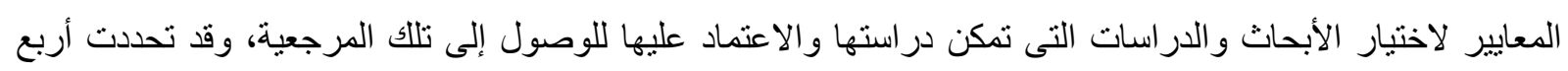

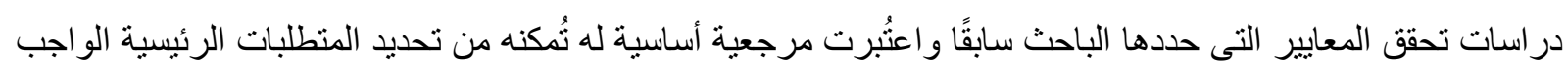
تو افرها عن تصميم المقابض الوظيفية. وبعد در اسة وتحليل الدر اسات السابقة، نوصل الباحث إلى قائمة مرجعية أولية تعد بمثابة نواة يمكن الاعتماد عليها والاستفادة

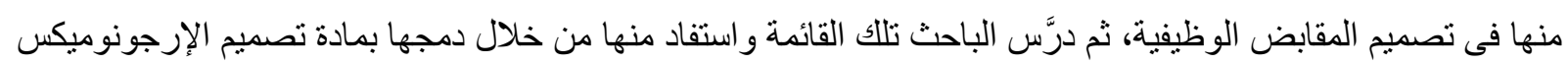

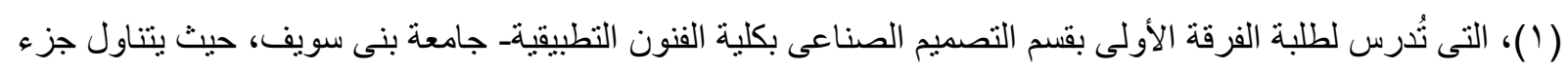
من توصيف المادة تدريب الطلاب على تصميم مقابض مجموعة منتو عة من الأدوات و العدد اليدوية المنتوعة، وتدريبهر على كيفية تطبيق تللك المنهجية من خلال وضع تصور لعملية التصميم المقترحة من منظور الطابع الإرجونوميكى، ونطبيق

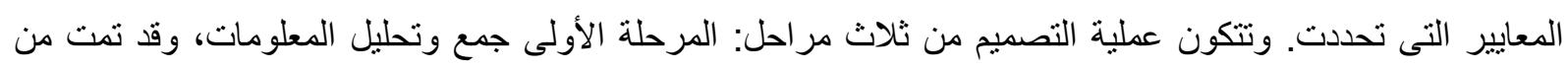

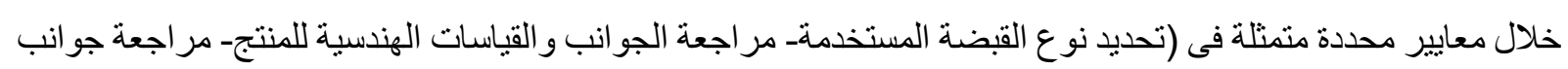
الأمان- تحديد المميزات و عيوب المنتج حسب اعتبار ات التصميم الرئيسيةـ وضع مقتر ح للتطوير). ثم تأتى المرحلة الثانية

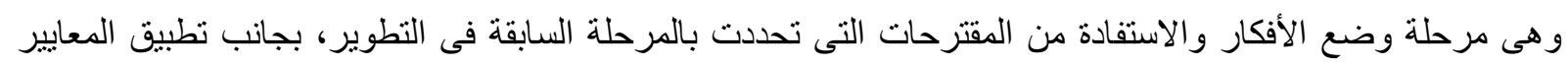
و الاشتر اطات الإرجونوميكية التى حددها الباحث سابقًا فى الأفكار المقترحة. ثم تأتى المرحلة الثالثة مرحلة مر اجعة التصميم

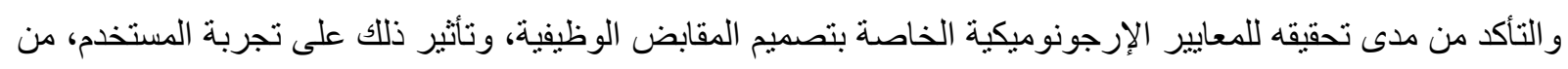
خلال تحويل التصميم المقترح إلى صورة مادية وعرضه على مجموعة من المستخدمين للاستخدام والتقيبيم من خلال الاستمارة المحددة، بجانب تصوير وتحليل الأوضاع المختلفة لقبضة المستخدم وتحليلها طبقًا للمعايير التى تحددت سابقًا. ومن التجربة السابقة تمكن الباحث وبمساعدة الطلاب من الوصول إلى تصميمات تراعى الجوانب الإرجونوميكية

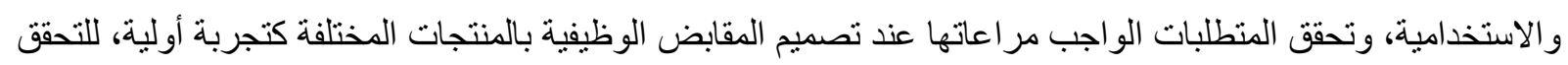
من مدى فاعلية المعايير المقترحة، والتوسع فى التجربة بصورة أثنمل وأكبر لتنثمل منتجات أكثر صعوبة وتعقيدًا، ولتصبح نواة تساعد الباحثين لاستكمال الدر اسات والأبحاث المتعلقة بهذا المجال. وبذلك يكون الباحث قد حقق هدف البحث الرئئيسى و المتمثل فى وضع قائمة بالاعتبار ات الإرجونوميكية الو اجب مر اعاتها من قبل المصممين ودارسى التصميم الصناعى عند تصميم المقابض الوظيفية المختلفة بالمنتجات.

هلم الإرجونوميكس يهذف إلى تحقيق الراحة والأمان عند استخدام المنتجات. تصميم المقابض الوظيفية بتلك المنتجات يحتل المرتبة الأولى من حيث العلاقة والتفاعل بين المستخدم والمنتج، حيث المثل تعد تلك القبضات الوسيلة الأولى لمساعدة المستخدم على استخدام المنتج والتحكم فيه. عدم ملائمة تصميم المقابض باختلاف صور ها يؤثر مباشرةً فى المستخدم، ويُشتعره بعدم الراحة وعدم القدرة على ولى استخدام المنتج بصورة مريحة و آمنة، بجانب نأثيره على نحو غير مباثر عليه على المدى الطويل من خلال ظهور مشكلات جسدية و عضلية لديه.

• كلما كان تصميم المقبض أفضل ملائمة للمستخدم، أدى ذللك إلى تقليل الأخطاء و الآثار المتعلقة بعملية الاستخدام.

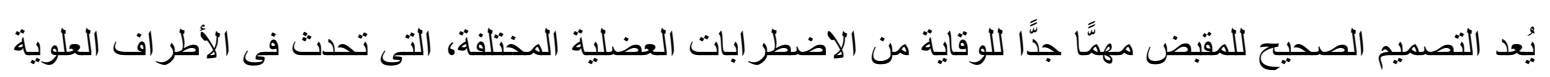
عند المستخدم بسبب طبيعة الاستخدام. 
• بمكن تقسيم نوع القبضة المستخدمة للإمساك بالمقابض الوظيفية إلى نوعين رئيسيين، هما: قبضة القوة ( Power

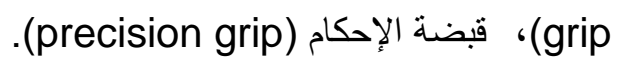

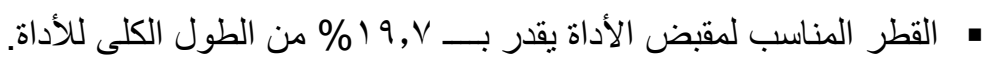

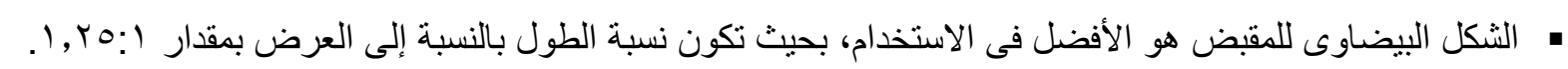

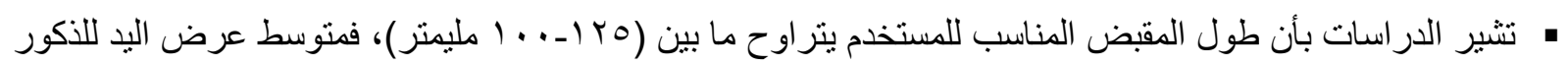

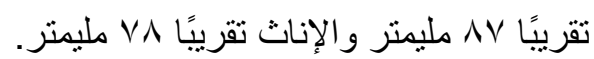

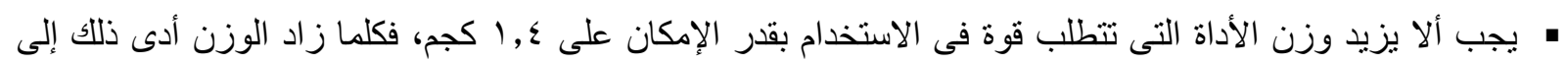
زيادة الجهد المبذول من قبل المستخدم. • يجب ألا يزيد وزن الأداة التى تتطلب دقة فى الاستخدام على 0, · كجم، فكلما زاد الوزن أدى ذلك إلى انخفاض الدقة بسبب قوة الضغط المؤثرة على يد المستخدم. • يفضل المستخدمون استخدام الأدوات و العدد ذات المقبض المنحدر بزاوية ـ ال درجات عن القبضات المستقيمة، كما تثير الدراسات إلى أن استخدام زاوية إمالة لتصميم المقبض ما بين زاوية (•ـــــ درجة) يمكن أن يقلل من الآثار السلبية الناتجة عن الاستخدام بالنسبة إلى معصم المستخدم.

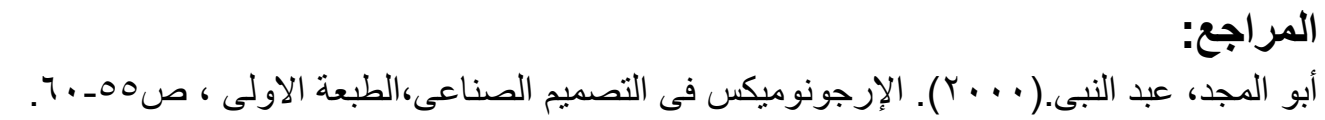

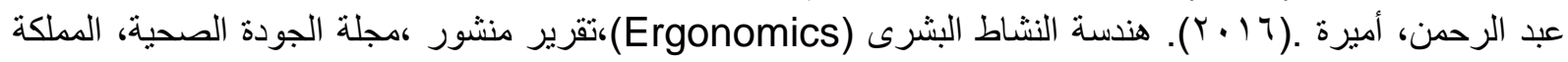
العربية السعودية. 'Abu Almajd, Eabd Alnabaa.(2000). al'iirjunumiks fa altasmim alsanaeaa,altubeat al'uwlaa , P55-60.

Balasubramanian, R., \& Santos, V. J. (2014). The human hand as an inspiration for robot hand development (Vol. 95): Springer.

Cochran, D. J., and Riley, M. W. (1986). An evaluation of knife handle guarding. Human factors, 28(3), 295-301 .

DOI: $10.1177 / 001872088602800305$

Controzzi, M., Cipriani, C., and Carrozza, M. C. (2014). Design of artificial hands: A review. The Human Hand as an Inspiration for Robot Hand Development, 219-246 .

DOI: 10.1007/978-3-319-03017-3

Dababneh, A., Lowe, B., Krieg, E., Kong, Y.-K., \& Waters, T. (2004). A checklist for the ergonomic evaluation of nonpowered hand tools. Journal of Occupational and Environmental Hygiene, 1(12), D135-D145.

DOI: $10.1080 / 15459620490883150$

Eabd Alruhmun, 'Amira .(2016). handasat alnashat albashari (Ergonomics),taqrir manshur ,mjlat aljawdat alsahyati, almamlakat alearabiat alsaeudiat.

Feix, T., Romero, J., Schmiedmayer, H.-B., Dollar, A. M., and Kragic, D. (2015). The grasp taxonomy of human grasp types. IEEE Transactions on human-machine systems, 46(1), 66-77 . DOI: $10.1109 /$ THMS.2015.2470657

Kong, Y.-K., \& Lowe, B. D. (2005). Optimal cylindrical handle diameter for grip force tasks. International Journal of Industrial Ergonomics, 35(6), 495-507 . 
DOI: 10.1016/j.ergon.2004.11.003

Schoenmarklin, R. W., \& Marras, W. S. (1989). Effects of handle angle and work orientation on hammering: II. Muscle fatigue and subjective ratings of body discomfort. Human factors, 31(4), 413-420 .

DOI: $10.1177 / 001872088903100405$

Patkin, M. (2001). A checklist for handle design. ergonomics australia on-line, 15 (supplement). In.

Schoenmarklin, R. W., \& Marras, W. S. (1989). Effects of handle angle and work orientation on hammering: II. Muscle fatigue and subjective ratings of body discomfort. Human factors, 31(4), 413-420.

PILOT-FLYING, F. C. P. W. PROCEEDINGS of the HUMAN FACTORS SOCIETY-26th ANNUAL MEETING-7982.

Selin, A.-S. (2003). Pencil grip: a descriptive model and four empirical studies.

Wang, C.-y., \& Cai, D.-c. (2017). Hand tool handle design based on hand measurements. Paper presented at the MATEC Web of Conferences.

DOI: $10.1051 /$ matecconf/201711901044

https://hireitdirect.co.uk/wp-content/uploads/2019/05/Hands-Holding-Tools-23602042.jpg (Access 1/11/2020)

http://m-quality.net/?p=8243 (Access 10/11/2020) 